\title{
Human SRF-related proteins: DNA-binding properties and potential regulatory targets
}

\author{
Roy Pollock and Richard Treisman \\ Transcription Laboratory, Imperial Cancer Research Fund Laboratories, Lincoln's Inn Fields London WC2A 3PX, UK
}

Serum response factor (SRF) is a transcription factor that binds the sequence $\mathrm{CC}(\mathrm{A} / \mathrm{T})_{6} \mathrm{GG}$ found in a number of growth factor-inducible and muscle-specific promoters. We describe the isolation and characterization of cDNA clones encoding a family of three human SRF-related DNA-binding proteins. Each of these RSRF (related to SRF) proteins contains an 86-amino-acid amino-terminal region related to the SRF DNA-binding domain: In RSRFC4 and RSRFC9, this region is identical, whereas that present in RSRFR2 differs by seven conservative amino acid substitutions. The DNA-binding specificity of the RSRF proteins, which recognize the consensus sequence CTA(A/T) $)_{4}$ TAG, is distinct from that of SRF. The entire RSRF common region is required for DNA binding, and the differential sequence specificity of the RSRFs and SRF is the result of differences in the basic amino-terminal part of this domain. The RSRF proteins bind DNA as dimers and can dimerize with one another but not with SRF. Although the RSRF mRNAs are expressed in many cell types, RSRFR2 mRNA is expressed at elevated levels in several B-cell lines. Consistent with this, extracts from many cell types form CTA(A/T) ${ }_{4}$ TAG-binding complexes that contain RSRF proteins, and oligonucleotides containing RSRF-binding sites function as promoter elements in transfection assays. Like SRF-binding sites, RSRF-binding sites are found in the regulatory sequences of a number of growth factor-inducible and muscle-specific genes, and we show that RSRF polypeptides are components of previously characterized binding activities that interact with these elements. We discuss the potential role of RSRF proteins in the regulation of these genes.

[Key Words: DNA-binding proteins; SRF; MADS box; SRE; MEF-2; growth factors; transcription; muscle-specific genes]

Received July 18, 1991; revised version accepted August 29, 1991.

Serum response factor (SRF) is a transcription factor that binds to the serum response element (SRE), a short regulatory sequence present in the promoters of many cellular immediate early genes such as c-fos and those encoding cytoskeletal actins (for review, see Treisman 1990). The SRF-binding site consensus sequence, CC(A/ $\mathrm{T}_{6} \mathrm{GG}$, is also found in a substantial number of musclespecific promoters, such as those of the cardiac and skeletal $\alpha$-actin genes (Minty and Kedes 1986). Functional analysis of both types of promoter has shown that mutations that block SRF binding abolish activity /for review, see Treisman 1990; also see Walsh and Schimmel 1988; Walsh 1989; Sartorelli et al. 1990). Moreover, the SRF sites from muscle-specific promoters can act as growth factor-regulated promoter elements in nonmuscle cells (Taylor et al. 1989; Walsh 1989; Tuil et al. 1990). These findings have led to the idea that SRF interacts with both types of promoter and that its activity is modulated by cell type- and promoter-specific factors (Boxer et al. 1989; Taylor et al. 1989).

SRF recognizes its operator as a dimer via a 90-aminoacid DNA-binding domain that appears unrelated to known DNA-binding structures. This domain comprises an amino-terminal basic region required for high-affinity DNA binding and a 50-amino-acid carboxy-terminal region that can direct subunit dimerization but cannot bind DNA (Norman et al. 1988; see Fig. 8, below). The DNA-binding domains of the Saccharomyces cerevisiae regulatory proteins $\mathrm{MCM} 1$ and ARG80 share $\sim 70 \%$ identity with that of SRF (Dubois et al. 1987a,b; Norman et al. 1988; Passmore et al. 1988; Ammerer 1990). In addition, several plant proteins contain a 56-amino-acid region highly related to the amino-terminal part of the SRF DNA-binding domain (Schwarz-Sommer et al. 1990; Sommer et al. 1990; Yanofsky et al. 1990; Ma et al. 1991). This region, which contains residues common to the entire group of proteins, has been termed the MADS (MCM1-Arg80-agamous-deficiens-SRF) box (SchwarzSommer et al. 1990). Although the DNA-binding specificity of MCM1 is clearly related to that of SRF (Hayes et al. 1988; Passmore et al. 1989|, the binding specificities of the other proteins are uncharacterized.

In addition to its function in subunit dimerization and DNA recognition, the SRF DNA-binding domain is sufficient to recruit to the c-fos SRE a second protein, p $62^{\mathrm{TCF}}$, which by itself exhibits no detectable DNA- 
binding activity (Herrera et al. 1989; Shaw et al. 1989; Schroter et al. 1990). It has been suggested that the role of p $62^{\mathrm{TCF}}$ is to integrate different signal transduction pathways at the SRE (Shaw et al. 1989; Graham and Gilman 1991). The activity of many MCM1 operators is likewise determined by the interaction of MCM1 with a variety of cell type-specific or pheromone-regulated accessory proteins (Bender and Sprague 1987; Keleher et al. 1988, 1989; Errede and Ammerer 1989; Ammerer 1990). As with SRF, these interactions require only the MCM1 DNA-binding domain (Ammerer 1990; M. Primig and G. Ammerer, in prep.).

In a search for other proteins that might bind the c-fos SRE, we set out to isolate cDNAs encoding other human SRF-related proteins. Here, we describe the isolation of cDNAs encoding a family of such proteins. These RSRF (related to $\underline{\mathrm{SRF}}$ ) proteins bind the consensus sequence
$\mathrm{CTA}(\mathrm{A} / \mathrm{T})_{4} \mathrm{TAG}$. Intriguingly, this binding site, like the SRF-binding site, occurs in many muscle-specific and growth factor-regulated genes. Previous studies have implicated CTA $(\mathrm{A} / \mathrm{T})_{4} \mathrm{TAG}$ elements and their cognate binding factors in the activity of several muscle-specific promoters (Hobson et al. 1988, 1990; Braun et al. 1989; Gossett et al. 1989; Horlick and Benfield 1989; Mueller and Wold 1989; Horlick et al. 1990; Zhu et al. 1991). We demonstrate that RSRF proteins are components of previously characterized cellular binding activities that interact with these promoter elements.

\section{Results}

\section{Isolation of SRF-related cDNAs}

We first screened human placenta and Jurkat cell cDNA libraries by low-stringency hybridization with a DNA

\section{RSRFC4 and RSRFC9}

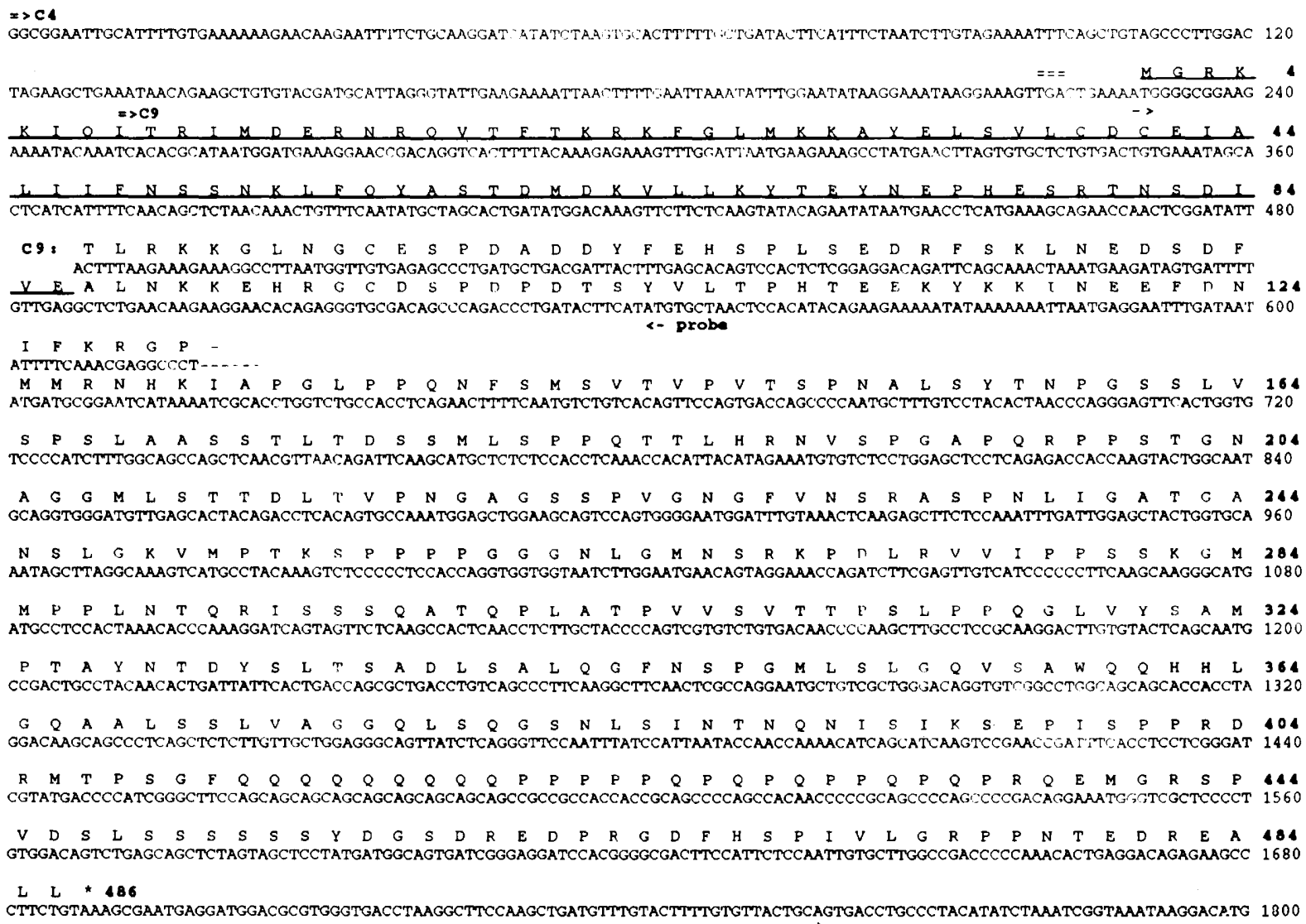

Figure 1. (See facing page for legend.) 
fragment spanning the SRF DNA-binding domain. Three phage were recovered, $\lambda$ RSRF1, $\lambda$ RSRF2, and $\lambda$ RSRF3, which contain reading frames encoding polypeptides with significant homology to the SRF DNA-binding domain. Because the sequence MKKAY/FE is present in both these proteins and in SRF, MCM1, and ARG80, we used a redundant oligonucleotide encoding this sequence as a probe in an additional screen. Two more phage were recovered, $\lambda$ RSRFC4 and $\lambda$ RSRFC9, which also contain an SRF-related region that is highly homologous to that of the other cDNAs.

The complete sequences of the $\lambda$ RSRFR2, $\lambda$ RSRFC4, and $\lambda$ RSRFC 9 cDNA inserts are shown in Figure 1 . Northern blot analysis of human kidney cell RNA revealed a predominant 6- to 7-kb RSRFC4 mRNA and a 2-kb RSRFR2 mRNA (data not shown); however, because these cDNAs contain open reading frames bounded by upstream in-frame stop codons, we have not pursued the isolation of full-length cDNA clones. The RSRFC4 open reading frame encodes a 486-amino-acid polypeptide of predicted $M_{\mathrm{r}} 52,250$. The RSRFC9 open reading frame is apparently identical to RSRFC4, apart from nucleotides $487-624$, which are replaced by a 132 nucleotide segment that encodes a related polypeptide sequence (see Fig. 1). Clone RSRFR2 contains an open reading frame encoding a 365-amino-acid polypeptide of predicted $M_{\mathrm{r}} 38,641$; although in this case we have as- signed the first ATG in the major reading frame as initiation codon, the reading frame extends 125 codons to its amino-terminal side and our assignment therefore remains tentative. The RSRF proteins all contain an 86amino-acid SRF-related amino-terminal region with seven conservative substitutions between the R-type and C-type proteins (Fig. 1, underlined region). We will refer to this region as the common region in subsequent discussion. Its amino-terminal part includes a MADS box closely related to all other SRF-like DNA-binding proteins, whereas its carboxy-terminal 30 amino acids are unique to the RSRF family (Fig. 1; also see Fig. 8, below). The predicted amino acid sequences were compared with the OWL sequence data base by using the Prosearch program. This revealed no other significant sequence homologies apart from that to other SRF-related proteins.

\section{Derivation of the RSRF-binding site consensus}

We produced the RSRFC4 and RSRFR2 polypeptides by in vitro translation and tested them for DNA-binding activity. They exhibited nonspecific DNA-binding activity, but no binding to several SRE and SRE-derived sequences was detectable (data not shown). We therefore determined the RSRF sequence specificity by using a binding site selection method (Pollock and Treisman 1990). Complexes formed between in vitro-translated RSRF polypeptides and a pool of radiolabeled random

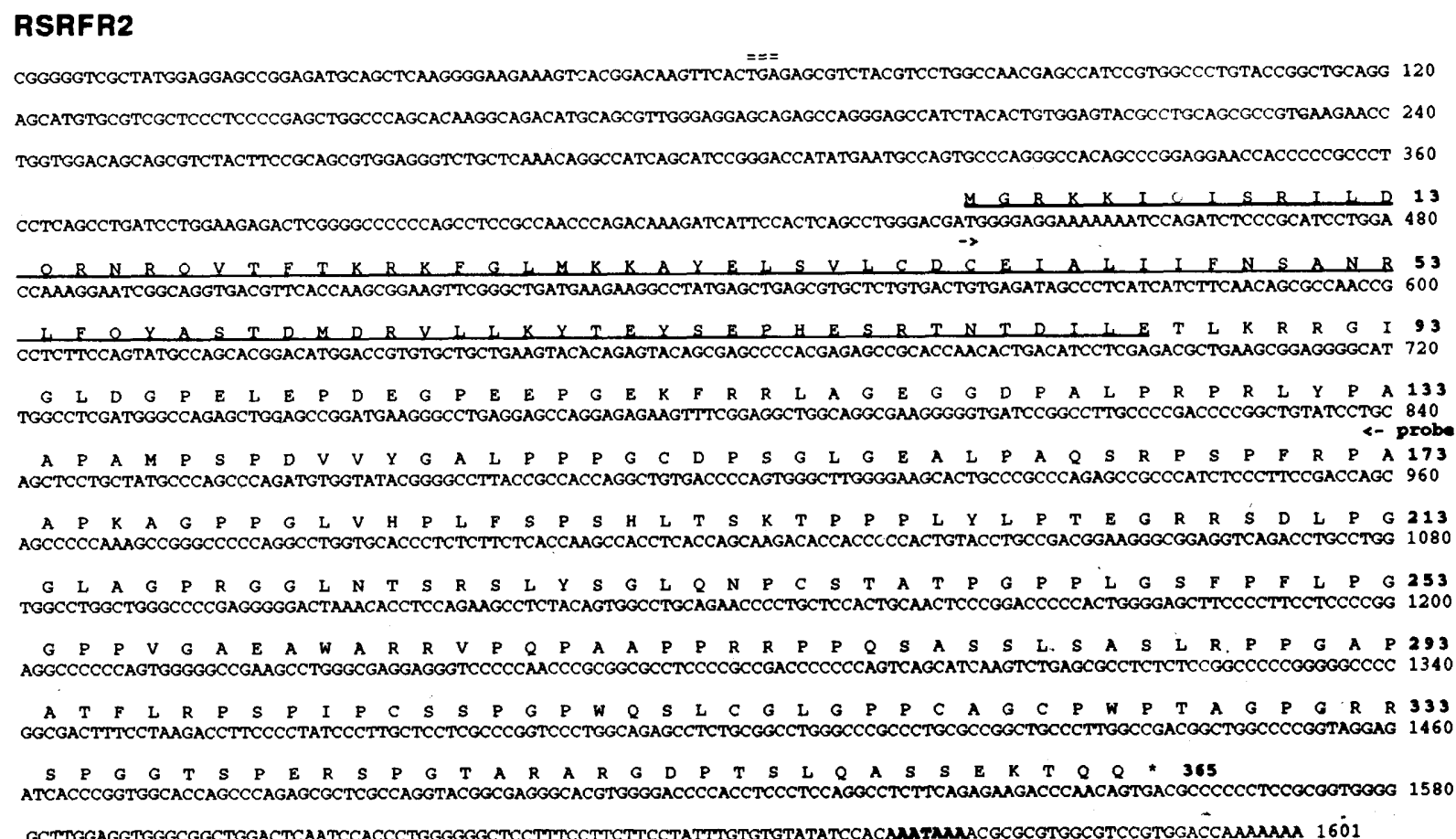

Figure 1. Sequences of the SRF-related cDNA clones RSRFR2, RSRFC4, and RSRFC9. The sequences of the cDNAs are shown with the common SRF-related domain underlined. Clone RSRFR3, not shown, extends from about RSRFR2 position 390 to the RSRFR2 polyadenylation site. In the case of RSRFC4 and RSRFC9, the end points of the individual cDNAs are indicated by arrows above the sequence; the variant region found in RSRFC9 is indicated above the main sequence. A potential polyadenylation sequence is indicated in boldface type, and the sequences used as probes for RNA analysis are marked by arrows. The termination codons that mark the 5' boundary of the open reading frames are indicated by double overlining. 
sequence oligonucleotides were purified by immunoprecipitation; the associated DNA was recovered, amplified with the polymerase chain reaction (PCR), and used for further rounds of selection. At each step, the recovered DNA was quantitated and tested by gel mobility-shift assay. For these experiments we used a truncated derivative of RSRFC4, RSRF $\Delta$ C4.T, which comprises RSRFC4 amino acids 1-105 fused to the human c-myc epitope $9 \mathrm{E} 10$, to allow immunoprecipitation of the protein by the 9E10 monoclonal antibody (Evan et al. 1985). Lysate programmed with RSRF $\triangle$ C4.T cRNA, but not unprogrammed lysate, selected an increasing proportion of input DNA with succeeding rounds of selection /see footnote to Table 1A). When this DNA was used in gel mobility-shift assays with the selecting lysate, increasing amounts of a specific DNA-protein complex were observed (data not shown). Although the DNA was selected by using the truncated epitope-tagged RSRF $\Delta$ C4.T polypeptide, full-length untagged RSRFC4 polypeptide binds it with comparable affinity (data not shown).

Table 1A shows the sequences of 61 RSRFC4-binding site oligonucleotides present after four rounds of selection with RSRF $\triangle$ C4.T. Of these sequences, 59 contain the consensus core element CTA(A/T) ${ }_{4} \mathrm{TAG}$, in which the outer TA dinucleotides are invariant. The presence of this motif in each of the selected oligonucleotides suggests that it represents the RSRF-binding site. The outermost CG is highly conserved, whereas several different patterns of AT base pairs are found in the central region. Some sequence bias is observed outside the core element region. Of the remaining two sequences, one probably represents a variant with a $C$ substitution within the central region, whereas the other, which appears to lack one of the central AT base pairs, may represent recognition of a half-site.

We could not detect binding of full-length RSRFR2 protein to DNA selected by RSRFC4 nor could we select sites for RSRFR2 with an epitope-tagged derivative, RSRFR2T, containing residues 1-290. We reasoned that this might arise from an inhibitory effect of the carboxyterminal domain of the protein on DNA binding and, therefore, performed site selections with an epitopetagged truncated version of the protein, RSRF $\Delta$ R2T, which contains only the SRF-related region (RSRFR2 residues 1-102). Binding sites selected by this polypeptide are shown in Table 1B. These sites are similar to those selected by RSRFC4 but contain a much higher proportion of half-sites that contain mismatches to the RSRFC4 consensus defined above. We conclude that the specificity of RSRFR2 DNA binding is very similar but not identical to that of RSRFC4.

\section{Interaction of RSRFC4 with natural CTA(T/A) ${ }_{4} T A G$ elements}

We then performed binding competition and carboxyethylation interference studies to confirm that the CTA(A/T) ${ }_{4}$ TAG element does represent the RSRFC4binding site and to examine its interaction with the protein in more detail. As will be reviewed in the Discus- sion, CTA(A/T) ${ }_{4}$ TAG elements are found in both growth factor-regulated and muscle-specific promoters; we chose sites from both classes for detailed analysis. One, from the promoter of the cellular immediate early gene N10 (Hazel et al. 1988; Changelian et al. 1989; Ryseck et al. 1989|, represents an example of the most common sequence recovered in the site selection CTATTTATAG. The second, from the muscle-specific creatine kinase (MCK) gene enhancer, represents a variant site, CTAAAAATAA, identified previously as a functional element and factor-binding site in this enhancer (Gossett et al. 1989; Horlick and Benfield 1989; Mueller and Wold 1989; Horlick et al. 1990).

To assess the significance of the conserved base pairs within the RSRF motif, we studied binding of RSRFC4, produced by in vitro translation, to the 28-bp oligonucleotide N1OWT, which contains the sequence CTATTTATAG. This oligonucleotide binds RSRFC4 efficiently and specifically as assessed by binding competition with unlabeled N10WT oligonucleotide (Fig. 2A, lanes 1-4). The binding affinity of the N10 oligonucleotide for SRF is at least 100-fold lower than that of the c-fos SRE /data not shown/. We then performed binding competition analysis with mutant derivatives of the N10 oligonucleotide. Oligonucleotides containing symmetrically placed mutations at invariant consensus positions /CCEATTTATGG, N1OM1; CGATTTATCG, N10M2; and CTITTTAAAG, N10M4), fail to compete for binding (Fig. 2A, lanes 5-12, 17-20), whereas an oligonucleotide containing symmetrically placed mutations at the highly conserved flanking positions (GTATTTATAC, N1OM3) competes but at much reduced efficiency (Fig. 2A, lanes 13-16). The N10M1 mutation creates a significant match to the SRF-binding site consensus, and this site consequently has 10 -fold increased affinity for SRF (10-fold less than the c-fos SRE; data not shown). Similar results were obtained when the MCK oligonucleotide was used as probe (data not shown).

To examine physical interactions between RSRFC4 protein and DNA in detail, we used a carboxy-ethylation interference assay. RSRFC4 was produced by in vitro translation and allowed to bind end-labeled probes containing the N10 and MCK RSRF sites that had been partially carboxy-ethylated by diethylpyrocarbonate (DEPC) treatment (Sturm et al. 1987). These probes have comparable affinity for RSRFC4 (see Fig. 6B, below). Complexed and free DNA were recovered from preparative mobility-shift gels, cleaved by piperidine treatment, and fractionated on sequencing gels. Because DEPC modifies both $A$ and $G$ at position 7, it provides an assay for DNA-protein contacts in the DNA major groove. The analysis shown in Figure 2B shows that modification of purines at each position throughout both binding sites interferes with RSRFC4 binding, with the exception of the inner base of the invariant TA dinucleotides. At these positions modification of the $\mathrm{A}$ residues has either no effect (MCK site) or a small effect (N10 site) on RSRFC4 binding, even though these base pairs are required for DNA binding. As will be discussed further below, the DEPC interference pattern for RSRFC4 bind- 
Table 1. RSRFC4- and RSRFR2-binding sites

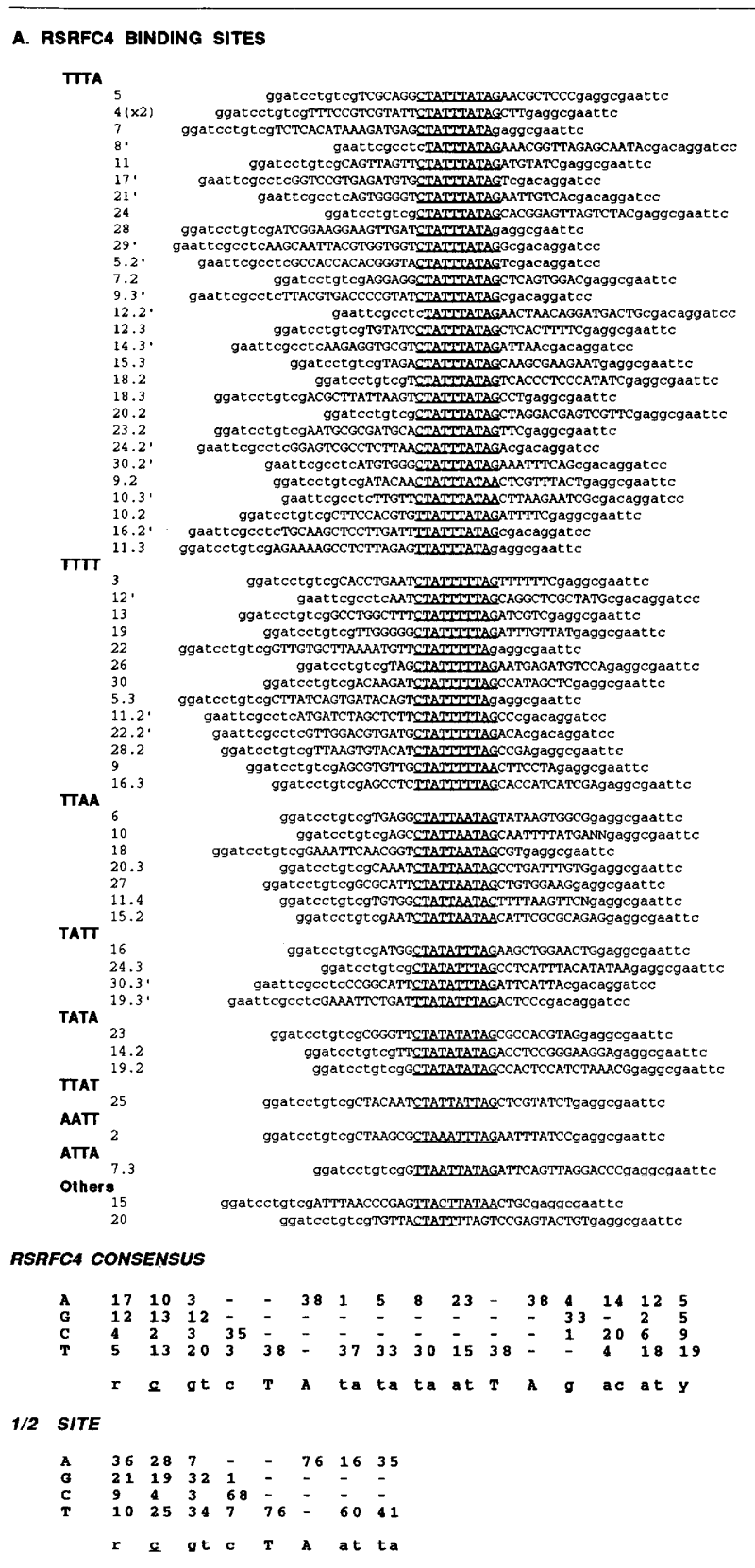

ing to the MCK site is identical to that published previously for the myotube factor MEF2 (Gossett et al. 1989).

\section{RSRF DNA-binding domain}

As noted above, the RSRF proteins all contain a common 86-amino-acid region; the amino-terminal 56 residues of this region comprise the MADS box homology found in all other SRF-related proteins. We used RSRF deletion mutants to investigate the role of the common region and MADS box sequence in DNA binding. Full-length RSRFC4 and its truncated derivative RSRFAC4.T, which contain the entire common region, bind the N10WT oli-

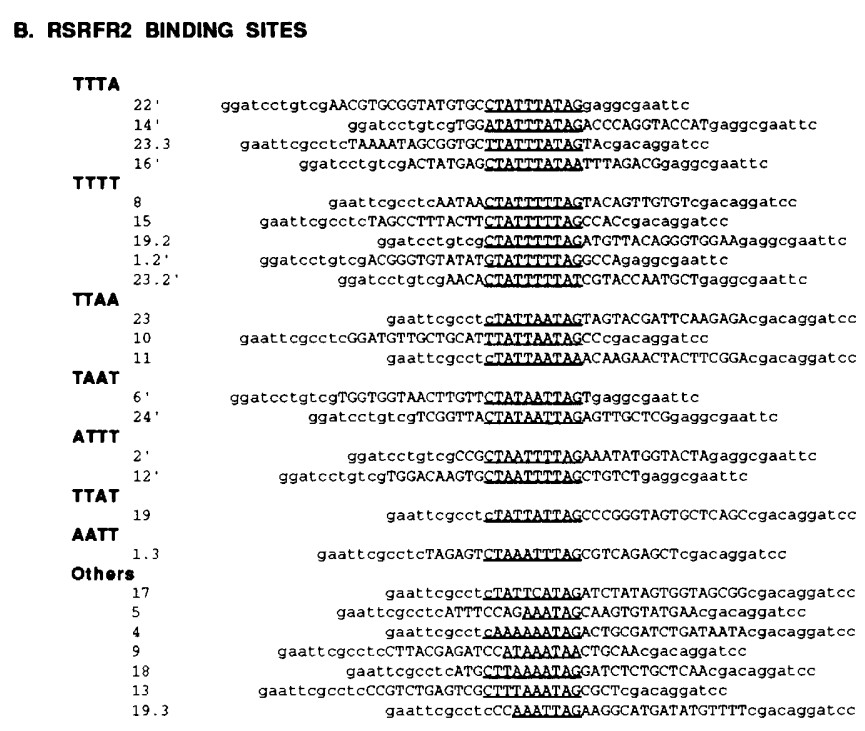

(A) RSRFC4-binding sites. DNA was selected by using rabbit reticulocyte lysate programmed with RSRF $\Delta C 4$.T cRNA, which encodes [RSRFC4(1-105/9E10)]. After four rounds of selection, DNA was purified by gel mobility shift and analyzed by DNA sequencing. Proportional recovery of oligonucleotide probe during the site selection with RSRF $\Delta$ C 4 .T lysate was $0.7 \%, 0.6 \%$, $5.4 \%$, and $24.5 \%$, comparable to that achieved with SRF; unprogrammed lysate did not select specific DNA. The oligonucleotides are aligned by the homologous A/T-rich consensus sequence present in each and grouped according to the sequence of the central quartet of AT base pairs. (Below) Data are summarized as consensus sequences for whole sites and half-sites. To eliminate systematic sequence bias arising from overlap with primer sequence, only those core elements at least $3 \mathrm{bp}$ from the primers were used to generate the consensus (Pollock and Treisman 1990). (B) RSRFR2-binding sites. Sequences of oligonucleotides selected by RSRF $\Delta$ R2.T [RSRFR2(1-102/ 9E10|]. The oligonucleotides are aligned by the homologous A/T-rich consensus sequence present in each and grouped according to the sequence of the central quartet of AT base pairs. A number of apparent half-sites were also recovered in this experiment and are aligned so as to maximize sequence conservation at the right.

gonucleotide efficiently (Fig. 3A, lanes 1,2). However, DNA binding by the deletion mutant RSRFC4(1-69), which retains the MADS box sequences but lacks the carboxy-terminal part of the common region, is not detectable (Fig. 3A, lane 3). The entire RSRF common region, including the sequences to the carboxy-terminal side of the MADS box, is thus required for efficient DNA binding.

We then exploited the difference in sequence specificity between the RSRF proteins and SRF to locate the region of the DNA-binding domain that determines binding specificity. Previous studies showed that the basic region of the SRF DNA-binding domain is essential for high-affinity DNA binding but not for dimerization. 

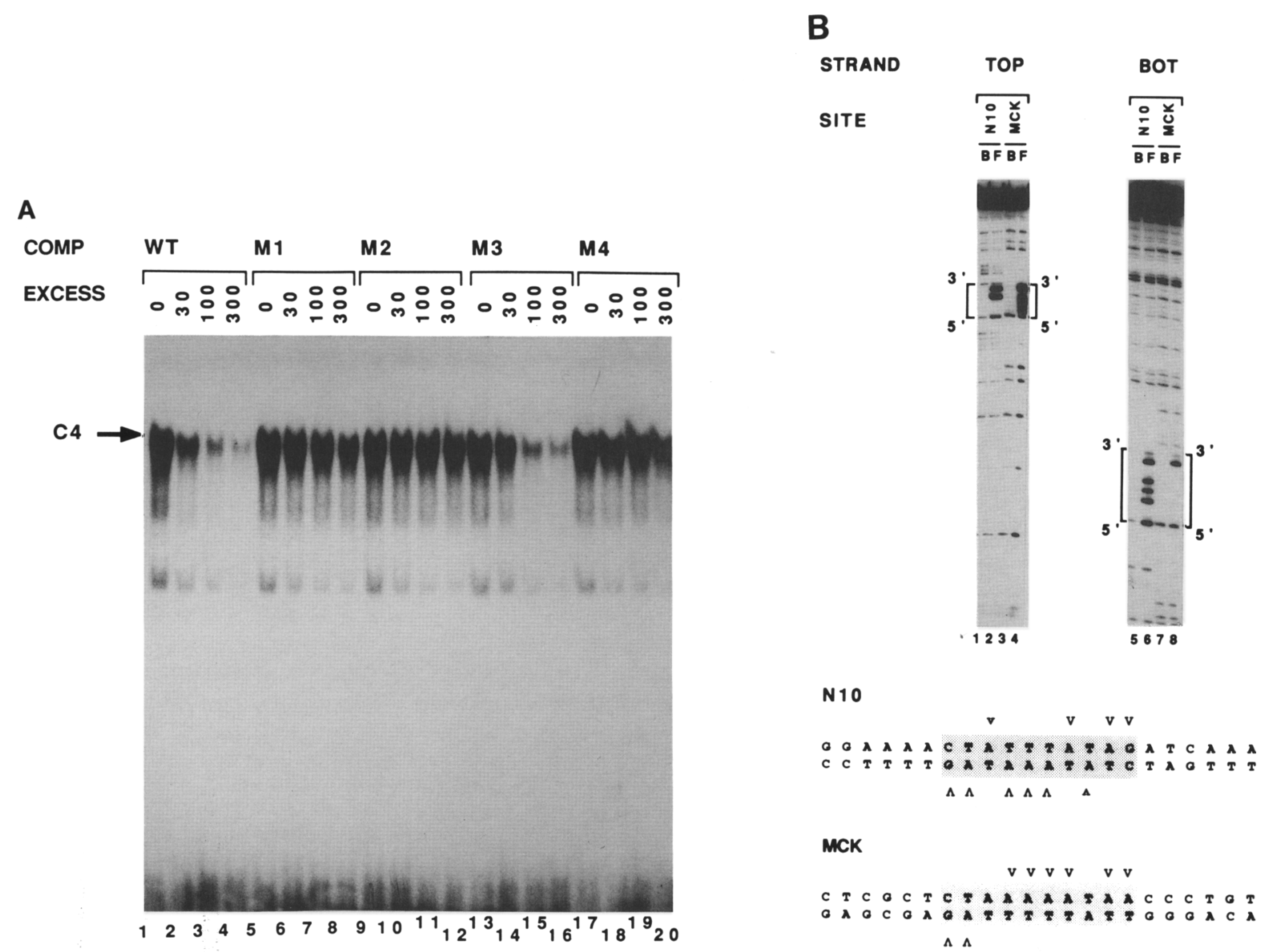

Figure 2. Analysis of RSRFC4-DNA interaction. (A) Binding competition analysis of RSRFC4 binding. Complexes were formed between the full-length RSRFC4 polypeptide and the N10 oligonucleotide, and varying amounts of competing oligonucleotide were included in the binding reactions as indicated. (Lanes 1-4) Competition by unlabeled N10WT oligonucleotide; (lanes 5-20) competition by the mutant oligonucleotides N10M1-4 (see text). (B) DEPC interference analysis of RSRFC4 binding to the N10 and MCK enhancer RSRF-binding sites. Complexes between RSRFC4 and end-labeled, partially carboxy-ethylated N1OWT and MCK probes and unbound probes were purified from a native gel and the DNA was cleaved with piperidine. (Lanes $1,3,5,7)$ DNA from complexes $(B)$; (lanes $2,4,6,8)$ unbound DNA (F). (Bottom) Sequences of the sites with a summary of the data. Symbols indicate partial interference.

To test whether the basic region actually determines sequence specificity, we analyzed the sequence specificity of a hybrid protein, C4/SRF, in which the basic region of RSRFC4 is joined to the dimerization and carboxy-terminal domains of SRF (for details, see Fig. 8, below). This protein was used for binding site selection, and the selected DNA was analyzed in the binding competition experiment shown in Figure 3B. Binding of C4/SRF protein to the selected DNA is effectively competed by excess unlabeled N10WT oligonucleotide but not by the nonbinding mutant N10M2; both wild-type and mutated c-fos SRE oligonucleotides fail to compete for binding (Fig. 3B, lanes 1-5). These results suggest that the majority of the selected oligonucleotides contain RSRFbinding sites, and sequence analysis confirmed that the specificity of the C4/SRF protein is virtually identical to that of RSRFC4 (Table 2). Differences between the basic regions of the RSRF and SRF DNA-binding domains therefore account for their different binding specificities.

\section{$R S R F$ proteins dimerize specifically with each other}

The detection of SRF-related mammalian proteins raises the possibility that these proteins and SRF might form heterodimers with novel properties. To investigate this, we first verified that the RSRF proteins bind DNA as dimers and then assessed their dimerization specificity. Gel mobility-shift analysis was used to demonstrate that RSRFC4 binds DNA as a dimer and that RSRFC4 and RSRFR2 can form heterodimers. When full-length and truncated RSRFC4 proteins were produced by cotranslation, three DNA-protein complexes were detectable in gel mobility-shift assays, corresponding to the short and long RSRFC4 homodimers and the long-short heterodimer; their relative abundance is dependent on the ratio of the different polypeptides present (Fig. 4A, cf. lanes 1 and 2 with lanes 3-6). Chemical cross-linking experiments confirmed that in solution RSRF proteins form dimers rather than higher-order oligomers /data not 


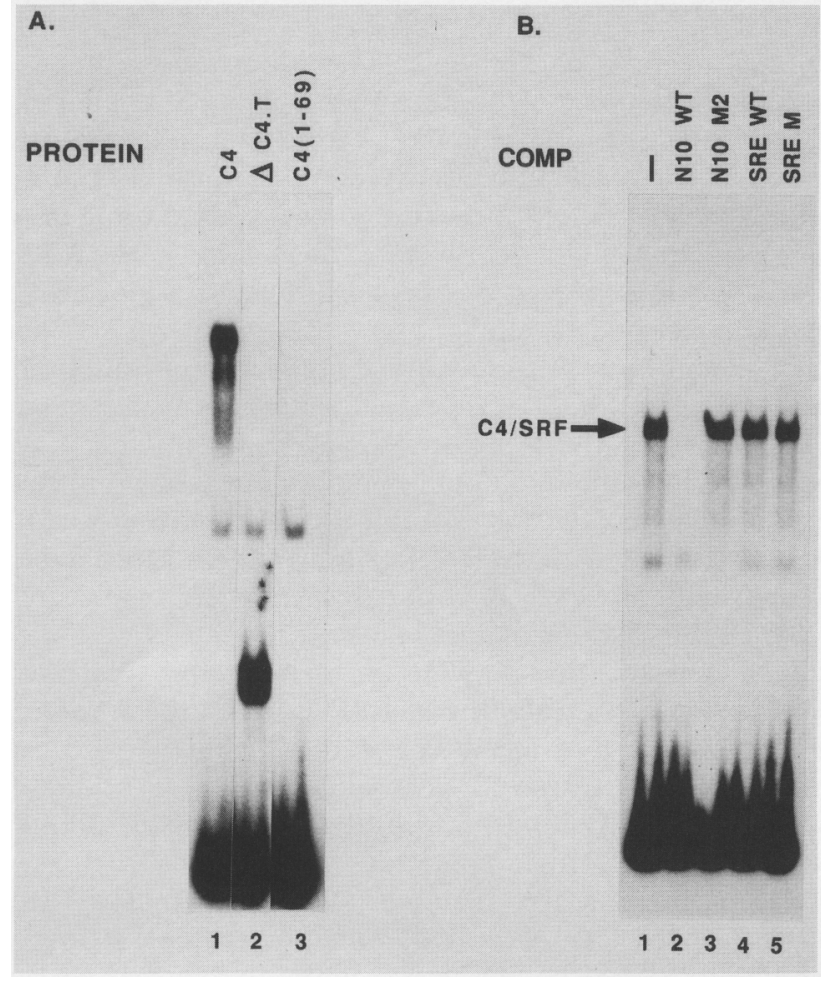

Figure 3. Analysis of the RSRFC4 DNA-binding domain. $(A)$ The whole conserved region is required for high-affinity DNA binding. The indicated RSRFC4 polypeptides were produced by cell-free translation and tested for DNA binding to the N10WT oligonucleotide. (Lane 1) RSRFC4(1-486); (lane 2) RSRFC4(1105); (lane 3) RSRFC4(1-69). (B) The basic region determines sequence specificity. DNA was selected by the chimeric protein C4/SRF [RSRFC4(1-30)/SRF(170-508)] and the $4 \times$ selected oligonucleotide pool used for binding competition analysis with C4/SRF protein. (Lane 1) No competitor oligonucleotide; (lanes 2-5) binding competition with 200-fold molar excess of oligonucleotides N10WT (lane 2), N10M2 (lane 3), c-fos SRE (lane 4), and c-fos SRE* (lane 5). (For sequences of these oligonucleotides, see the text and Materials and methods.)

shown). Similar results were obtained with cotranslation of full-length RSRFC4 and short form RSRFR2; although in this case, the heterodimer band was much weaker, suggesting that the interaction is not as strong as that of RSRFC4 homodimers (Fig. 4A, lanes 7-12).

We then used an immunoprecipitation assay to investigate whether the RSRF proteins could form stable dimers with SRF itself. Cotranslation in vitro was used to produce excess 9E10 epitope-tagged RSRFC4 short form (RSRF $\Delta$ C4.T), together with small amounts of either full-length RSRFC4, SRF, or a RSRFC4 derivative that lacks the DNA-binding domain, RSRFC4(105-486). Efficient and stable dimerization under the assay conditions should allow recovery of the untagged polypeptide by immunoprecipitation with the 9E10 antiserum. As expected, the untagged RSRFC4 that contains the DNAbinding domain is efficiently immunoprecipitated, whereas the RSRFC4 deletion derivative that lacks the DNA-binding domain is not (Fig. 4B, cf. lanes 1 and 2 with 5 and 6). In contrast, untagged SRF is not recovered, indicating that RSRFC4 and SRF do not form stable heterodimers under these conditions (Fig. 4B, cf. lanes 1 and 2 with 3 and 4/. A similar series of experiments was performed with the RSRFR2 derivative RSRFR2.T, which contains residues 1-290 with a carboxy-terminal 9E10 epitope. This protein can dimerize with RSRFR2 and RSRFC4 but fails to interact with SRF (Fig. 4B, cf. lanes 7-10 with 11-14). We conclude that the RSRF proteins and SRF do not interact efficiently in solution.

\section{RSRF $m R N A$ s are expressed in many cell types}

To examine RSRF mRNA levels in different cells, we performed RNase protection analysis by using specific probes complementary to the SRF-related and carboxyterminal regions of the RSRF mRNAs. Results are shown in Figure 5. The RSRFC4 probe spans the region of divergence between RSRFC4 and RSRFC9 and can therefore differentiate between these two mRNAs. The RSRFC4 mRNA, which generates a 312-nucleotide product, appears to be ubiquitously expressed; in this analysis, all RNAs also generate the 256-nucleotide product characteristic of RSRFC9 mRNA (or other as yet unidentified RSRF mRNAs that diverge from RSRFC4 at the same point). Low levels of RSRFR2 mRNA, which generates a 394-nucleotide product, are detected in many cell lines and tissues; however, elevated levels of RSRFR2 mRNA are found in several B-cell lines such as Daudi, Namalwa, and PGF.

\section{RSRF-like binding activities are ubiquitous in cell extracts}

We used gel mobility-shift analysis to investigate the expression of RSRF-like binding activities in a variety of cell extracts. In particular, we wished to confirm the presence of RSRF proteins in muscle cells, because the RSRF-binding site is found in muscle-specific promoters and the RSRFC4 DEPC interference data are identical to those observed previously for the myotube factor MEF-2 (Gossett et al. 1989). We first used the N10WT oligonucleotide to examine specificity of factor binding in different extracts. In each case, a single major complex was detected; formation of this complex was effectively prevented by excess N10WT oligonucleotide but not by the nonbinding mutant oligonucleotide N10M2. The complex comigrated with the complex formed with RSRFC4 produced by cell-free translation (data not shown). Specific complexes were observed in extracts from HeLa, NIH-3T3, CEM, Jurkat, Namalwa, and C2 myotubes and myoblasts (Fig. 6A lanes 1-21); in addition, similar complexes were observed with F9, 293, CV1, and COS-7 cell extracts (data not shown). Although high levels of the RSRFR2 mRNA are expressed in Namalwa and other B-cell lines, extracts of these cells formed no complexes distinguishable from those observed with non-B-cell extracts (Fig. 6A, cf. lanes 1-3 with 13-15). A more extensive analysis of binding activities in HeLa and NIH-3T3 
Table 2. The basic region determines sequence specificity

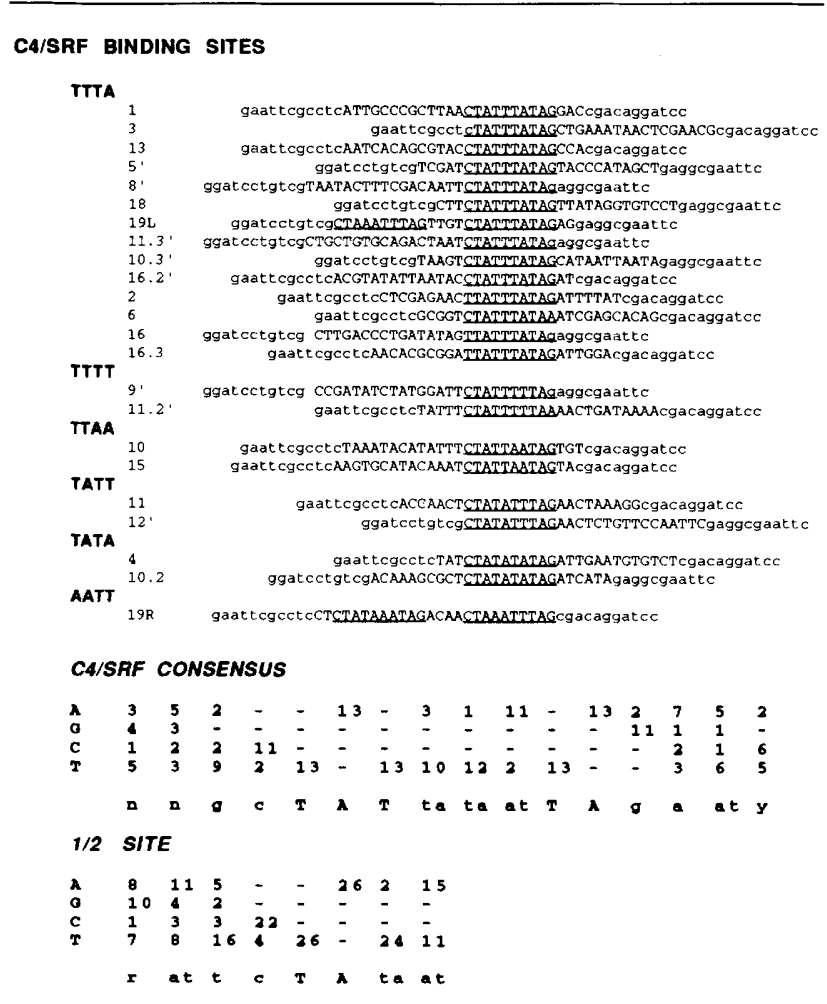

DNA was selected by the chimeric protein C4/SRF [C4(1-30)SRF(170-508)] by using SRF antiserum, and analyzed as described in the footnote to Table 1. The oligonucleotides are aligned by the homologous $\mathrm{A} / \mathrm{T}$-rich consensus sequence present in each and grouped according to the sequence of the central quartet of AT base pairs. (Below) Data are summarized as consensus sequences for whole sites and half-sites.

cell extracts with the other mutant oligonucleotides as competititors showed that the binding specificity of the factor detected in these cells is the same as that of RSRFC4 (data not shown).

We used an antiserum prepared against the common carboxy-terminal part of the RSRFC4 and RSRFC9 protein to confirm that complexes formed between extract proteins and the N1OWT and MCK probes do contain RSRF proteins. Under the assay conditions used, our antiserum will quantitatively and specifically further retard complexes formed between in vitro-translated RSRFC4 and the N10WT probe (Fig. 6B, cf. lanes 1-4). Complexes formed by either the N1OWT or MCK probes and $\mathrm{C} 2$ muscle myoblast and myotube extracts are partially reactive with this antiserum, but not with preimmune serum (Fig. 6B, cf. lanes 7, 10, 13, and 16 with 6, 9, 12 , and 15). Because these complexes did not react quantitatively with the antiserum, we conclude that they must be heterogeneous and contain other RSRF proteins in addition to the RSRFC4 and/or RSRFC9 proteins. We obtained similar results with HeLa and NIH-3T3 cell extracts (data not shown).

\section{The RSRF-binding site defines a promoter element}

We then tested whether the RSRF-binding site can function as a promoter element. Single or double copies of the wild-type or mutated N10 oligonucleotides were inserted at the $5^{\prime}$ side of the thymidine kinase (TK) promoter, which directs transcription of the chloramphenicol acetyltransferase (CAT) gene in plasmid pBLCAT2 (Luckow and Schutz 1987). Because the activity of SRFbinding sites is serum inducible, we tested the activity of each site in both serum-deprived and serum-stimulated cells. The parental plasmid exhibits low activity in these cells, and its activity is not affected by serum stimulation (Fig. 7, lanes 1,2). Insertion of one copy of the N10WT oligonucleotide stimulates basal activity only slightly, and two copies give a significant increase over background; however, in both cases, the activity appears to be slightly serum-inducible (about fivefold; Fig. 7, cf. lanes 1 and 2 with 3-6). The serum inducibility of the element appears greater (up to 10-fold) when the amount of transfected DNA is reduced (data not shown). In contrast, the N10M2 and N10M4 oligonucleotides, which do not detectably bind RSRF proteins, exhibit no activity; the N10M3 oligonucleotide, which binds with reduced affinity, is also inactive (Fig. 7, cf. lanes 11-16 with 5 and 6). As expected, oligonucleotide NlOMl, which blocks RSRF binding but contains the weak SRFbinding site CCATTTATGG, exhibits greater inducibility than any of the other oligonucleotides (Fig. 7, cf. lanes 3-6 with 7-10).

To test whether the activity of the N10 element could be potentiated in vivo by overexpression of the RSRF polypeptides, we transfected cells with RSRF expression plasmids in combination with the reporter plasmids described above. No effects on expression of the reporters in either serum-starved or serum-stimulated cells were observed (data not shown).

\section{Discussion}

\section{$R S R F$ protein family}

In this report we have described the structure and properties of a set of novel mammalian proteins that contain a common amino-terminal SRF-related DNA-binding domain. These RSRF proteins are not related to previously characterized proteins apart from those with SRFlike DNA-binding domains. The carboxy-terminal regions of RSRFC4 and RSRFC9 are identical apart from a region of $\sim 40$ amino acids adjoining the DNA-binding domain, which may result from alternative exon usage. In contrast, the carboxy-terminal region of the RSRFR2 protein is unrelated to that of RSRFC4 and RSRFC9. The high proportion of proline and glutamine residues in the RSRF carboxy-terminal domains is consistent with these proteins playing a role as transcriptional activators (Courey et al. 1989; Mermod et al. 1989). The RSRFC4 and RSRFC9 mRNAs are expressed in many cell types, and RSRFR2 mRNA is expressed at especially high levels in B-cell lines.

The RSRF proteins have a distinct sequence specificity from SRF, recognizing the consensus sequence CTA/A/ 
A

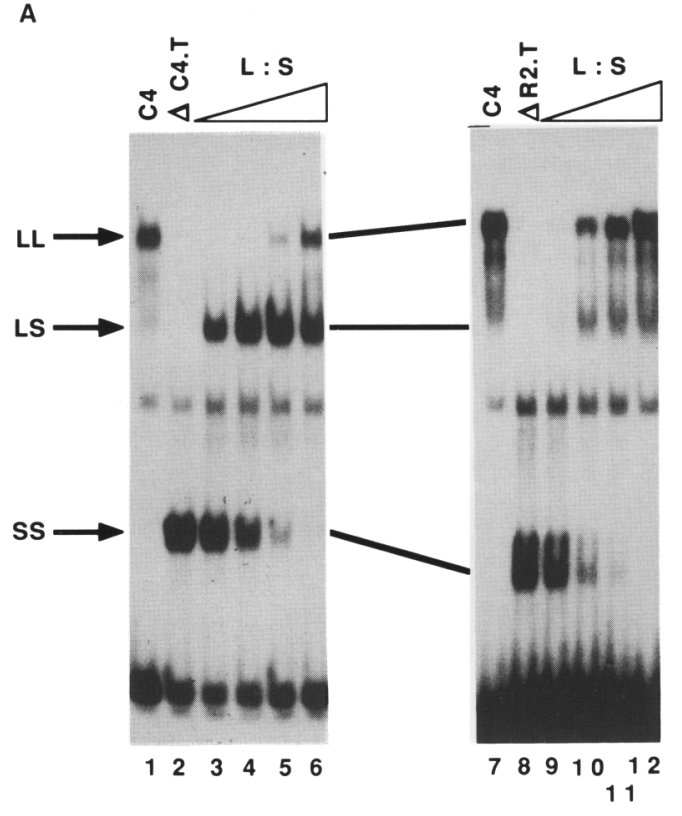

B

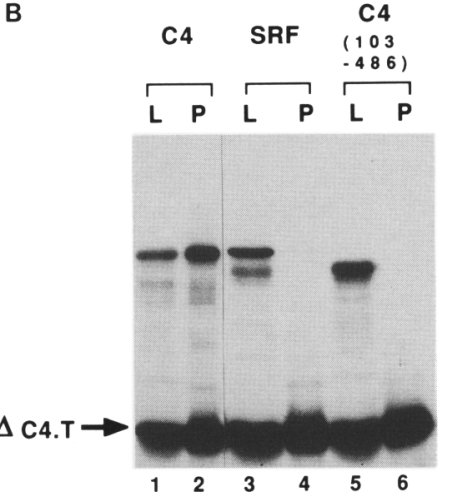

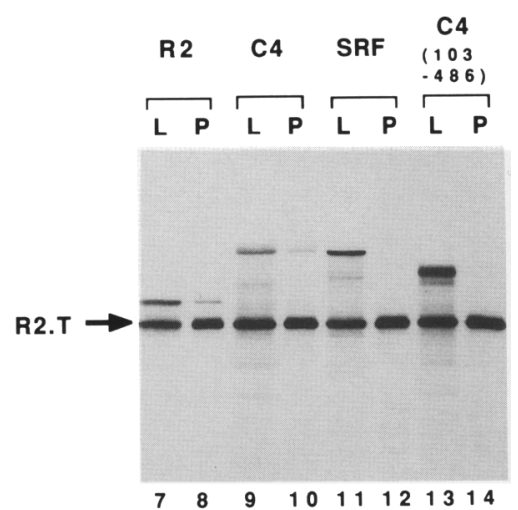

Figure 4. Dimerization of RSRF proteins. $(A)$ Analysis by DNA-binding activity using the N10WT oligonucleotide. (Lanes 1-6) Dimerization of RSRFC4. Full-length RSRFC4 and the short form RSRF $\triangle \mathrm{C} 4$.T were synthesized by cellfree translation, either individually (lanes 1,2) or together, with increasing fulllength to short form ratio (lanes 3-6). (Lanes 7-12) Heterodimerization between RSRFC4 and RSRFR2. Full-length RSRFC4 and the RSRFR2 short form RSRF $\triangle$ R2T were synthesized by cell-free translation, either individually (lanes $1,2)$ or together with increasing RSRFC4 to RSRFR2 ratio (lanes 3-6). Positions of complexes formed by long and short form homodimers, and by heterodimers are indicated by LL, SS, and LS respectively. $(B)$ Analysis by immunoprecipitation. Proteins were resolved on a $14 \%$ gel and fluorographed. (Lanes 1-6) Coprecipitation of proteins with RSRFC4.T; (lanes 7-14) coprecipitation of proteins with RSRFR2.T. Excess RSRF $\Delta$ C4T or RSRFR2T cRNA was cotranslated with cRNA encoding full-length RSRFC4 (lanes 1,2,9,10), SRF (lanes 3,4,11,12), RSRFC4(103-486) (lanes 5,6,13,14), or full-length RSRFR2 (lanes 7,8). Proteins were then immunoprecipitated with the 9E10 antiserum. (Lanes 1,3,5,7,9,11,13) Total proteins synthesized (L); (lanes 2,4,6,8,10,12,14) immunoprecipitated proteins (P).

T) ${ }_{4}$ TAG. Nevertheless, like SRF sites, RSRF-binding sites are present in a number of growth factor-regulated and muscle-specific promoters, as discussed below. Extracts from many different cultured cell lines contain proteins that form complexes with RSRF-binding site oligonucleotides. These complexes react with an antiserum directed against the common RSRFC4 and RSRFC9 carboxy-terminal region and must therefore contain RSRF proteins. Because only a portion of the complexes react with our antiserum, it is probable that other, as yet uncharacterized, members of the RSRF family exist. Binding activities specific for the CTA(A/T) ${ }_{4}$ TAG sequence have been reported previously: Our data show that the RSRFC4 and RSRFC9 proteins are components of a binding activity referred to as TARP (Hobson et al. 1988; Horlick et al. 1990), ARBF (Mueller and Wold 1989), and MEF2 (Gossett et al. 1989) and indicate that this activity must contain multiple RSRF polypeptides. Variation in RSRF expression levels in different cells and heterodimerization of different RSRF proteins may diversify further the range of RSRF-binding activities in the cell, with corresponding effects on the function of cellular RSRF-binding sites.

\section{SRF-like DNA-binding domain}

Seven SRF-like DNA-binding domains from human, plant, and yeast proteins are compared in Figure 8. All of the proteins contain a region of $\sim 56$ residues that has been termed the MADS box (Schwarz-Sommer et al. 1990). Two groups of the proteins, the RSRFs and SRFMCM-ARG80, contain conserved regions of $\sim 80$ amino acids, which comprise the MADS box and the adjacent carboxy-terminal 30 amino acids. When the sequences are aligned, the amino- and carboxy-terminal borders of these regions virtually coincide, suggesting that they constitute a structural domain (Fig. 8, cf. uppercase residues); however, there is little obvious homology between the two groups in the carboxy-terminal part of this domain. We find that the entire RSRF common region is required for high-affinity DNA binding, in agreement with previous studies of the SRF and MCM1 DNAbinding domains (Norman et al. 1988; Ammerer 1990). We suggest that the minimal region for high-affinity DNA binding by other MADS box proteins will also include sequences to the carboxy-terminal side of the MADS box region.

We showed previously that the amino-terminal basic part of the SRF DNA-binding domain is required for high-affinity DNA binding but not for subunit dimerization (Fig. 8; Norman et al. 1988). In this work we extended this analysis to show that the basic region determines the sequence specificity of the RSRF proteins and is thus likely to make sequence-specific protein-DNA contacts. In all of the SRF-like proteins apart from ARG80, the basic region contains two segments of predicted $\alpha$-helix: Helix I contains both conserved framework and variable residues, whereas helix II is virtually identical among all family members (Fig. 8). We propose that the amino-terminal part of the basic region, including helix I, is involved in sequence-specific DNA contact for two reasons. First, this region differs between RSRFC4 and RSRFR2, which our site selection analysis shows have subtly different DNA-binding specificities. Second, MCM1 and SRF, which differ significantly 

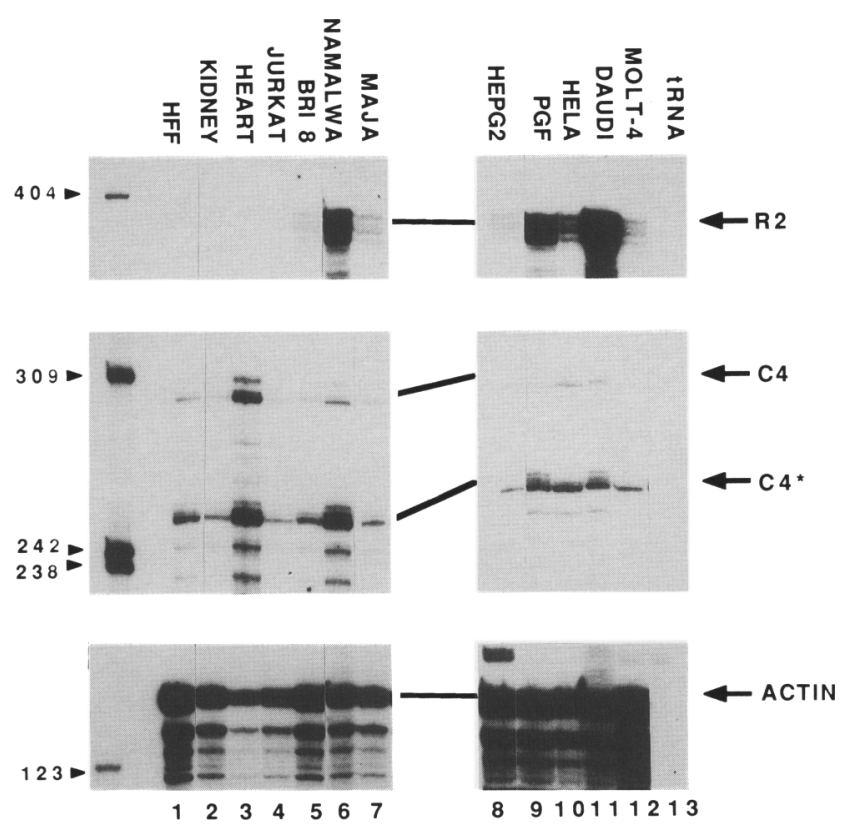

Figure 5. Expression of RSRF mRNAs in different cell types. Total cellular RNA $(10 \mu \mathrm{g})$ from the indicated cell lines or yeast tRNA $(10 \mu \mathrm{g})$ was analyzed by RNase protection mapping by using probes specific for RSRFR2 (top), RSRFC4 and RSRFC9 (middle), and $\gamma$-actin (bottom). Exposure was $16 \mathrm{hr}$ apart from the left middle panel, which was $40 \mathrm{hr}$. Nuclease-protected fragments characteristic of intact RSRFR 2 and RSRFC 4 mRNA are marked by arrows as $\mathrm{R} 2$ and $\mathrm{C} 4$, respectively; the product marked as $\mathrm{C}^{*}$ is diagnostic of RSRFC9 or other variants that diverge from the $\mathrm{C} 4$ sequence at this point. (For details of probes used, see Materials and methods; Fig 1.).

within the basic region, also have overlapping but nonidentical sequence specificities (Hayes et al. 1988; Passmore et al. 1989; J. Wynne, S. Dalton, and R. Treisman, unpubl.).

Although the MADS box region presumably represents a conserved structural unit present in all of the proteins, the significance of the divergent carboxy-terminal segments of these DNA-binding domains remains unclear. The DNA-binding domains of SRF-like proteins have other functions such as subunit dimerization and, in the case of SRF and MCM1, interactions with accessory proteins; perhaps these functions are differentiated by their divergent carboxyl termini. Our experiments with chimeric RSRF-SRF proteins suggest that the specificity of dimerization is not determined solely by the variable carboxy-terminal region (R. Pollock and R. Treisman, unpubl.). Preliminary experiments suggest that the RSRF proteins do not interact with p62 ${ }^{\text {TCF }}$ (A. Rogers, R. Pollock, and R. Treisman unpubl.), but it remains possible that accessory proteins, as yet uncharacterized, can associate with RSRF DNA-binding domains.

The binding activity of the SRF DNA-binding domain can be modulated by phosphorylation at a casein kinase II site located $\sim 50$ residues to its amino-terminal side (Manak et al. 1990; Manak and Prywes 1991; Marais et al. 1991). No such kinase sites are present in the RSRF proteins. However, it remains possible that the apparent inactivity of the intact RSRFR2 protein in in vitro DNAbinding assays might reflect a failure to make appropriate modifications of the protein in the cell-free translation system. Further studies are needed to clarify this issue.

\section{Interaction of RSRF proteins with DNA}

The consensus for the RSRFC4-binding site, CTA/A/ $\mathrm{T})_{4} \mathrm{TAG}$, was determined by binding site selection in vitro. The symmetrically placed invariant TA dinucleotides presumably reflect similar contacts made by the two subunits of the protein; and in agreement with this idea, symmetrically placed mutations at these positions block DNA binding. The closer spacing of invariant dinucleotides of the RSRFC4 site compared with the SRF site presumably reflects differences in the positions and character of residues within the RSRF basic region that contact the DNA. RSRF sites are not perfectly symmetric, with the asymmetric sequences TTTT and TTTA preferred in the central region. Other SRF-like DNAbinding domains such as SRF and MCMl also bind sequences with some degree of asymmetry (Passmore et al. 1989; Pollock and Treisman 1990; J. Wynne and R. Treisman, unpubl.). Outside the central AT-rich core sequence, there is a strong preference for the flanking $5^{\prime} \mathrm{C}$ and $3^{\prime} \mathrm{G}$.

A significant proportion of the oligonucleotides selected by the RSRFR2 DNA-binding domain and a small number of oligonucleotides selected by RSRFC4 contain mismatches at one of the conserved TA dinucleotides and thus resemble half-site matches to the RSRFC4 consensus. Mismatches of this type in SRF sites cause a 5- to 10-fold reduction in binding affinity (Leung and Miyamoto 1989) but have relatively little effect at MCM1 sites (Passmore et al. 1988; Tan et al. 1988; J. Wynne and R. Treisman, unpubl.). It is therefore possible that single mismatches at invariant positions have only small effects on RSRFC4 binding; therefore, the spectrum of RSRF-binding sites in vivo may be somewhat broader than our deduced consensus.

We examined the physical interactions between RSRFC4 and two naturally occuring binding sites by DEPC interference analysis. The interference pattern at the mouse muscle creatine kinase gene enhancer site is identical to that reported previously for the MEF-2-binding activity (Gossett et al. 1989). Assuming that in this assay, interference with binding reflects direct prevention of DNA-protein contact, our data suggest that the RSRF proteins make major groove contacts with the DNA throughout one complete turn of the DNA helix. A similar analysis of SRF also shows major groove DNAprotein contact throughouts one helical turn (S. Dalton and $\mathrm{R}$. Treisman, unpubl.).

\section{Potential target promoters for RSRF proteins}

We screened the GenBank nucleotide sequence data base for matches to the sequence $\left.(\mathrm{C} / \mathrm{T}) \mathrm{TA}(\mathrm{A} / \mathrm{T})_{4} \mathrm{TA} / \mathrm{G} / \mathrm{A}\right)$ with the Nsearch motif search program (M. Sternberg, pers. comm.). RSRF-binding sites were considered potentially functional if they satisfied one or more of the fol- 
A

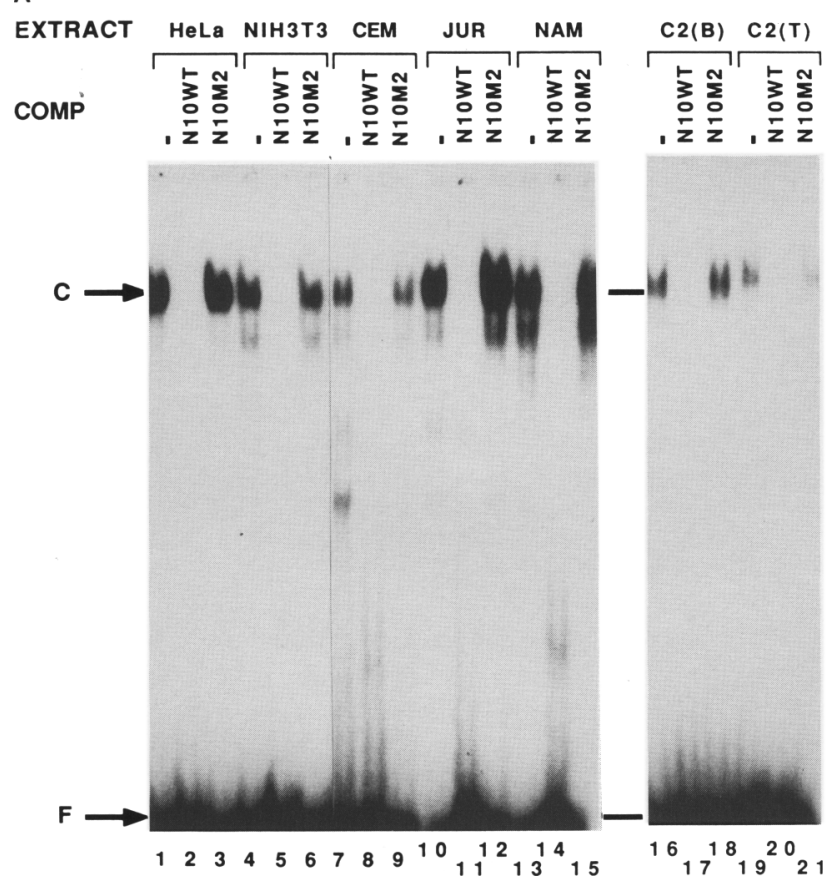

B

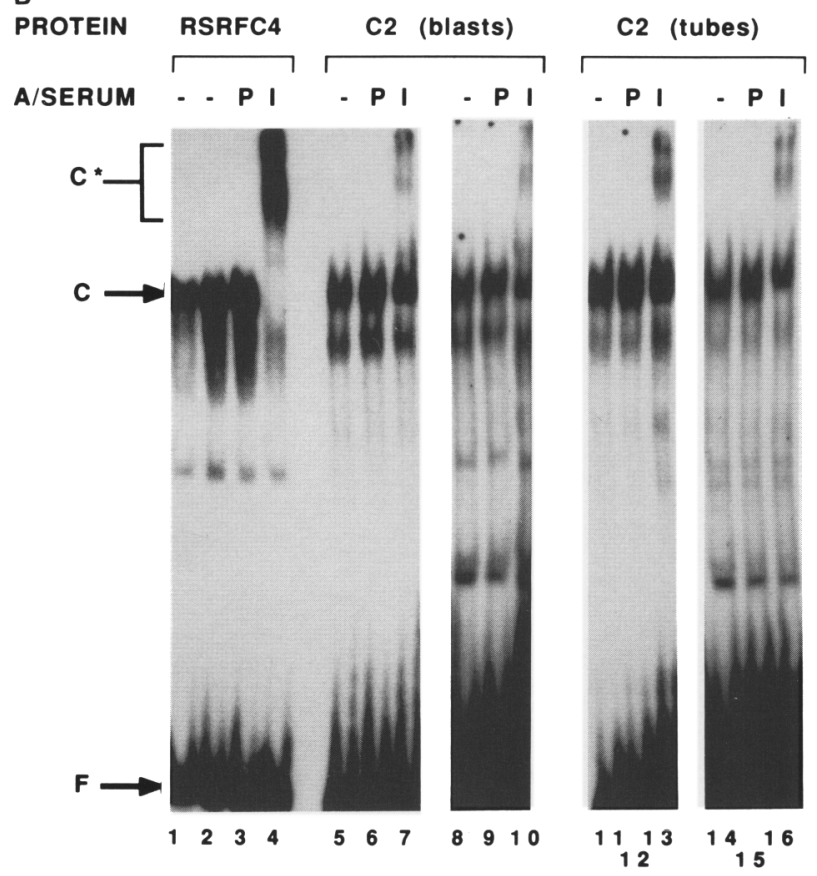

Figure 6. Detection of RSRF proteins in extracts from different cell types. (A) Analysis of nuclear extracts by binding competition. Extracts $(10 \mu \mathrm{g})$ were analyzed by gel mobility-shift analysis with the N10WT oligonucleotide as probe, in the presence of either no competitor oligonucleotide (lanes $1,4,7,10,13,16)$ or with a 100 -fold molar excess of N10WT (lanes 2,5,8,11,14,17) and N10M2 (lanes $3,6,9,12,15,18)$ oligonucleotides. The major specific complex $(C)$ comigrates on these gels with that formed by full-length RSRFC4 produced in vitro. $(B)$ Reactivity of $C 2$ cell RSRF-like proteins with anti-RSRFC4/C9 antiserum. Proteins were analyzed with the MCK (lanes 1,8-10,14-16) and N10WT (lanes 2-7,11-13) probes. (Lanes 1-4) RSRF protein produced by in vitro translation (1 $\mu$ l); (lanes 5-10), C2 myoblast extract proteins; (lanes 11-16) C2 myotube proteins. Binding reactions were preincubated with preimmune serum (lanes $3,6,9,12,15)$ or immune serum (lanes $4,7,10,13,16)$. The positions of the main RSRF complex and the immunoreacted complexes are indicated.

lowing criteria: (1) occurrence within known promoter elements of the gene concerned; $(2)$ repeated occurrence of the motif within short lengths of DNA close to RNA initiation points or enhancer elements; (3) evolutionary conservation of single elements in different species; and (4) occurrence at positions at which proteins are bound in vivo. The results of the search show that in general, RSRF-binding sites occur as potential regulatory elements in the same type of genes as SRF-binding sites, namely growth factor-regulated or muscle-specific promoters. The significance of many other matches to the consensus remains unclear. Many Alu repeat sequences contain potential RSRF sites, as well as a number of TATA boxes, raising the possibility that RSRF proteins may regulate the access of TFIID, as observed with certain homeo box proteins (Ohkuma et al. 1990; K. Visvanathan and S. Goodbourn, pers. comm.).

Many promoters and enhancers of muscle-specific or muscle-enhanced genes contain RSRF-binding sites, and in several cases, their functional significance has been confirmed directly by gene transfer experiments and protein-binding studies. These binding sites contribute to the in vivo activity of the MCK (Gossett et al. 1989; Horlick and Benfield 1989) and myosin light-chain 1/3 (Donoghue et al. 1988; Wentworth et al. 1991) gene enhancers, and the myosin light-chain type $2 \mathrm{~A}$ (Braun et al. 1989; Zhu et al. 1991) and creatine kinase B (Hobson et al. 1988, 1990) promoters. These sites have been shown

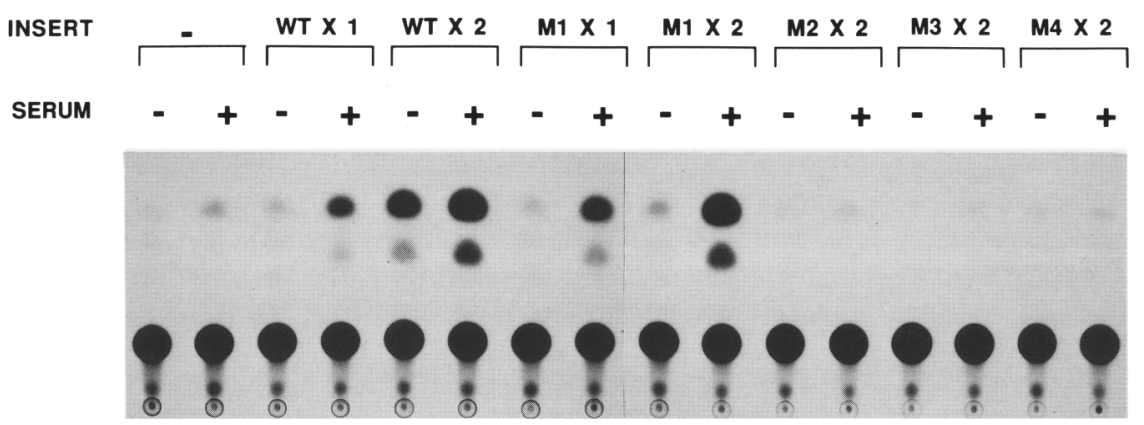

Figure 7. Promoter activity of intact and mutated RSRF-binding sites in NIH-3T3 cells. One or two copies of the indicated RSRF-binding site oligonucleotides /see Fig. 2C) were inserted into pBLCAT2, and the resulting plasmids were transfected into NIH-3T3 cells. Cells were either serum starved for $50 \mathrm{hr}$ (lanes 1,3,5, $7,9,11,13,15)$ or serum starved and restimulated for $8 \mathrm{hr}$ (lanes 2,4,6,8,10, $12,14,16)$. Activity of the cotransfected $\beta$-galactosidase reference plasmid varied $<1.5$-fold between the transfections. 


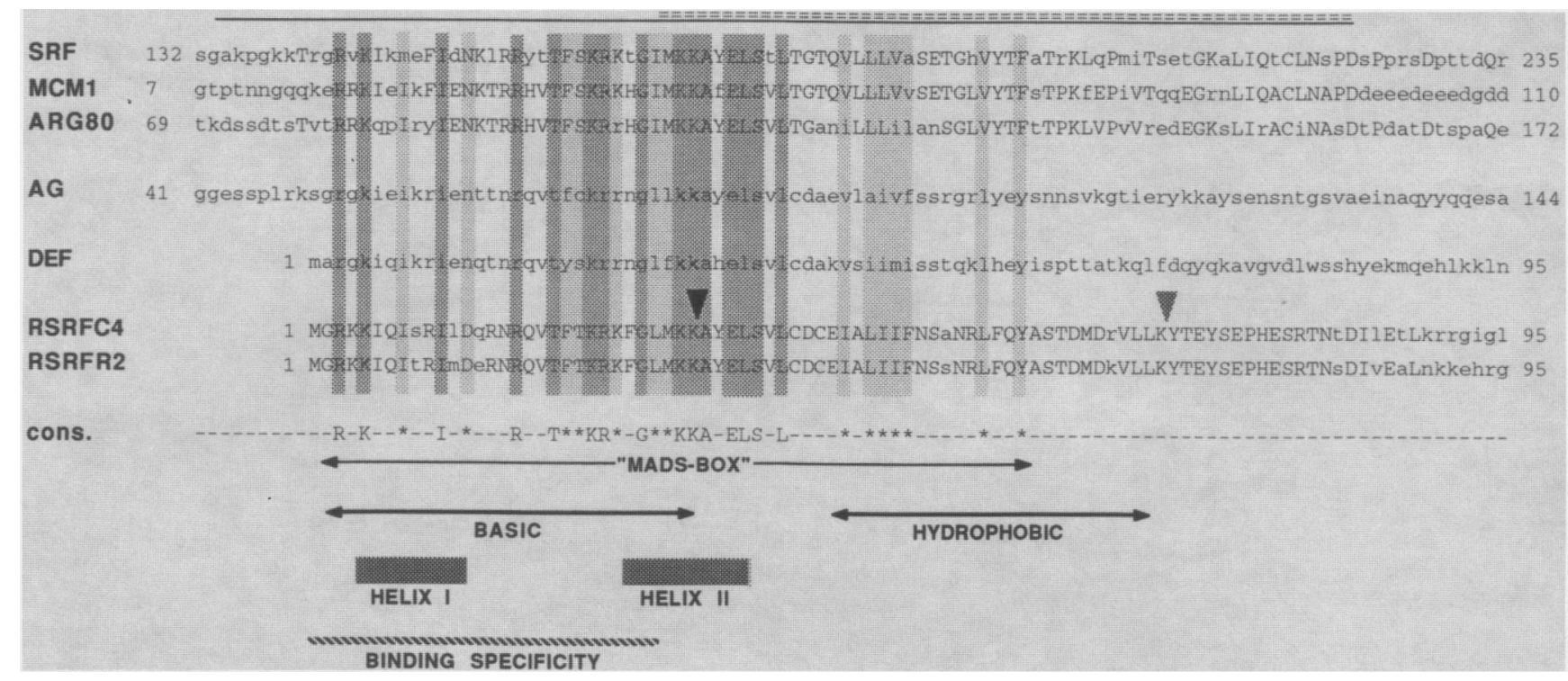

Figure 8. SRF-like DNA-binding domains. Partial sequences of the SRF, MCM1, ARG80, Ag, Def, and the RSRFC4 and RSRFR2 proteins are shown. Shown are regions of SRF sufficient for DNA binding (solid line) and dimerization (double dashes). Positions of identity or highly conservative substitution between all family members are indicated by heavy and light shading, respectively, and these residues are indicated below the sequences. The solid triangle above the RSRFC4 sequence indicates the location of the restriction site used to generate C4/SRF; the shaded triangle indicates the location of the restriction site used to generate RSRFC4/169). (Bottom) The extent of the basic and hydrophobic regions of the DNA-binding domains, two predicted regions of $\alpha$-helix (Eliopoulos et al. 1982), and the specificity-determining region of the RSRFs (for discussion, see text).

to bind common factors with an RSRF-like binding specificity both in vitro (Hobson et al. 1988; Gossett et al. 1989; Horlick et al. 1990) and in vivo (Mueller and Wold 1989); as discussed above, the RSRFC4 and RSRFC9 proteins are components of these binding factors. RSRF sites present in muscle-specific promoters appear to be functionally interchangeable with sites that are not in strictly muscle-specific promoters (Horlick et al. 1990).

Several nonmuscle promoters regulated by extracellular signals contain RSRF-binding sites, including those of the cellular immediate early genes N10/nur77/NGF1-B and c-jun (Hattori et al. 1988; Hazel et al. 1988; Milbrandt 1988; Brun et al. 1989; Ryseck et al. 1989) and the Epstein-Barr virus (EBV) BZLFl gene (Flemington and Speck 1990). The precise roles of these sites in the regulation of these genes remain unclear. The N10 gene contains sites at -262 and -297 , which both bind RSRFC4 in vitro /this study; R. Pollock and R. Treisman, unpubl.), and at -894 (Changelian et al. 1989; Ryseck et al. 1989). The c-iun RSRF-binding site, at -59 , is in a conserved region required for activation of Jun transcription by protein kinase $\mathrm{C}$ in $\mathrm{HeLa} \mathrm{TK}^{-}$cells (Angel et al. 1988). Our in vitro-binding studies show that this site can bind both RSRFC4 and HeLa cell RSRF-like proteins (R. Pollock and R. Treisman, unpubl.); it also appears to be bound by protein in vivo (V. Bardwell and R. Treisman, unpubl.). The phorbol ester-responsive promoter of the EBV BZLF1 gene contains a both a consensus RSRFbinding site and a number of apparent half-sites that can nevertheless cross-compete for factors binding to the c-jun RSRF site (Flemington and Speck 1990). Potential binding sites for both SRF and RSRF proteins are also found in the immediate early enhancers of both simian and human cytomegalovirus (Boshart et al. 1985; Jeang et al. 1987), although, again, the biological significance of these sites remains obscure.

\section{Function of RSRF proteins in vivo}

In mouse NIH-3T3 cells, RSRF sites function as positively acting promoter elements that are slightly inducible by serum stimulation. Because mutations that block RSRF binding also block activation, it is likely that this reflects the binding of RSRF-related proteins in vivo. However, although these properties suggest that the RSRF proteins themselves are involved in transcriptional activation, we have not consistently observed transcriptional activation in transient transfection experiments with RSRF cDNAs. The serum inducibility of RSRF sites suggests that the activity of the RSRF proteins may also be linked to extracellular signaling pathways. It is thus reasonable to propose that RSRF proteins, like SRF, are involved in the regulation of both muscle-specific and growth factor-regulated transcription.

There are two major ways in which the activity of RSRF sites may be differentially regulated. The first way is by expression of different RSRF proteins in different cell types. For example, the high levels of RSRFR2 mRNA in B-cell lines suggest that this protein is expressed at elevated levels in B cells, and we are currently developing RSRFR2-specific antisera to test this directly. A previous report proposed that the types of factors that interact with the MCK enhancer RSRF site may change upon fusion of $\mathrm{C} 2$ myoblasts (MBF1) to myotubes (MEF2; Gossett et al. 1989); however, we observed no such change in our experiments. A second mechanism 
Mammalian SRF-related proteins

for differential regulation would be by the interaction of ubiquitous RSRF proteins with cell-specific accessory or associated proteins. This view has also been invoked previously to explain the function of SRF- and RSRF-binding sites in both muscle-specific and ubiquitously growth factor-inducible promoters (Taylor et al. 1989; Walsh 1989; Horlick et al. 1990; Sartorelli et al. 1990). Because many muscle-specific genes contain binding sites for myogenic factors such as the MyoD-E12 complex in close proximity to either RSRF- or SRF-binding sites, an attractive possibility is that the myogenic factors can specifically interact with both the RSRFs and SRF itself. This possibility is intriguing because the RSRF and SRF DNA-binding domains are of a common structural class that is known to participate in transcription factor interactions.

\section{Materials and methods}

Isolation and sequencing of RSRF CDNA clones

Phages $\lambda$ RSRFR $1-\lambda$ RSRFR 3 were identified by screening $\lambda$ gt 11 cDNA libraries from human placenta (Clontech) and Jurkat $T$ cells (Krissansen et al. 1986) with an SRF DNA-binding domain probe (SmaI-BglII; nucleotides 779-1094; Norman et al. 1988) at low stringency. $\lambda$ RSRFRl appears to lack an A residue at codons 4-5 and was not examined further. Phages $\lambda$ RSRFC4 and $\lambda$ RSRFC9 were recovered from the placental library by using the redundant MKKAY/FE oligonucleotide probe as described (Norman et al. 1988). The $\lambda$ RSRFR 2 and $\lambda$ RSRFC4 inserts were sequenced completely on both strands; the sequence of $\lambda$ RSRFC 9 was confirmed by using appropriate oligonucleotide primers.

\section{Plasmids}

All plasmids were constructed by standard and PCR methods and verified by sequence analysis; full details are available on request. Plasmids for in vitro translation of RSRFC4 and RSRFR2 polypeptides were based on pT7 $\beta$ Sal, in which translation is directed by the human $\beta$-globin $5^{\prime}$-untranslated region and initiation codon (Norman et al. 1988), and were linearized with EcoRI for transcription by $\mathrm{T} 7$ polymerase. Underlined sequences indicate the 9E10 epitope (Evan et al. 1985). Plasmid pT7C4(1-486) encodes RSRFC4 amino acids 1-486. Plasmid pT7 $\triangle$ C4.T encodes RSRFC4 amino acids 1-105/MEQKLISEEDLNMLESTCRST (XbaI used to linearize). Plasmid pT7C4(105-486) encodes M/RSRFC4 amino acids 105-486.Plasmid pT7C4/SRF encodes RSRFC4 amino acids 1-30/SRF amino acids 170-508, derived from pT7 $A$ ATG (Norman et al. 1988). Plasmid pT7R2(1-365) encodes RSRFR2 amino acids 1-365. Plasmid pT7R2.T encodes RSRFR2 amino acids 1-290/MEQKLISEEDLNM. Plasmid pT7DR2.T encodes RSRFR2 amino acids 1-102/ MEQKLISEEDLNM. Plasmids for RNase protection probes were constructed from pT7C4(1-486) and pT7R2(1-365), and linearized with $\mathrm{Ncol}$ for transcription. pC4SP6 contains RSRFC4 nucleotides $230-542$ and generates protected fragments of 312 and 256 nucleotides from RSRFC4 mRNA, and RSRFC9 mRNA, respectively. Plasmid pR2SP6 contains RSRFR2 nucleotides 444-838 and generates a 394-nucleotide protected fragment with RSRFR2 mRNA. For $\gamma$-actin mRNA, pSP6y-actin (Enoch et al. 1986) was used.

Plasmids pN10.WT $\times 1$, pN10.WT $\times 2$, pN10.M1 $\times 1, \mathrm{pN} 10 . \mathrm{M} 1 \times 2$, $\mathrm{pN} 10 . \mathrm{M} 2 \times 2, \mathrm{pN} 10 . \mathrm{M} 3 \times 2$, and $\mathrm{pN} 10 . \mathrm{M} 4 \times 2$ contain one or two copies of the appropriate oligonucleotide inserted into the $\mathrm{XbaI}$ site of pBLCAT2 (Luckow and Schutz 1987) in the sense orientation.
Oligonucleotides

Oligonucleotides were synthesized on an Applied Biosystems 380A machine.

MKKAY/FE: ATGAA(G/A)AA(G/A)GC(A/T/C/G)T(T/A)/T/ C)GA

N10WT: ctagAGGAAAACTATTTATAGATCAAAT/ctagATTTGATCTATAAATAGTTTTCCT

N10M1: ctagAGGAAAACCATTTATGGATCAAAT/ctagATTTGATCCEATAAATGGTTTTCCT

N10M2: ctagAGGAAAACGATTTATCGATCAAAT/ctagATTTGATCGATAAATCGTTTTCCT

N10M3: ctagAGGAAAAGTATTTATACATCAAAT/ctagATTTGATGTATAAATAC̄TTTCCT

N10M4: ctagAGGAAAACTTTTTAAAGATCAAAT/ctagATTTGATCTTTAAAAAGTTTTCCT

MCK: ctagaCTCGCTCTAAAAATAACCCTGTC/ctagaACAGGGTTATTTTTAGAGCTAGC

SRE: ctagAGGATGTCCATATTAGGACATCT/ctagAGATGTCCTAATATGGACATCCT

SRE * ${ }^{\star}$ ctagAGGATGTCGATATTACGACATCT/ctagAGATGTCGTAATATCGGACATCCT

\section{Dimerization immunocoprecipitation assay}

Binding reactions were set up on ice, comprising $20 \mu \mathrm{l}$ of buffer E (Pollock and Treisman 1990), $0.1 \mu$ l of 9E10 ascites fluid, $1 \mu 1$ of rabbit anti-mouse IgG and $5 \mu \mathrm{l}$ of reticulocyte lysate, and were then added to $10 \mu \mathrm{l}$ of packed volume of protein A-Sepharose beads (Pharmacia) preequilibrated in buffer E. After mixing in the cold for $3 \mathrm{hr}$, the beads were washed three times with $1 \mathrm{ml}$ of cold buffer $\mathrm{E}$ without BSA. The beads were boiled in SDS-PAGE loading buffer, and the eluted proteins were resolved by SDS-PAGE.

\section{Antibodies}

RSRFC4 codons 272-486 (BglII--EcoRI) were fused in-frame to glutathione $S$-transferase in plasmid $\mathrm{pGEX} 2$; fusion proteins were purified as described (Smith and Johnson 1988). Rabbits were immunized three times at 14-day intervals with $200 \mu \mathrm{g}$ of fusion protein in Freund's adjuvant and test-bled after 10 days. For antibody supershift experiments, binding reactions were incubated with $0.2 \mu \mathrm{l}$ of immune or preimmune serum for $30 \mathrm{~min}$ before addition of probes.

\section{Cell culture and transfection}

Mouse NIH-3T3 cells were transfected with $5 \mu \mathrm{g}$ of test plasmid and $2 \mu \mathrm{g}$ of pJATLACZ (M. Ellis, unpubl.; transfection efficiency control) by using the DEAE-dextran method (Sompayrac and Danna 1981), followed by shock with medium containing $10 \%$ dimethylsulfoxide (DMSO) for $2 \mathrm{~min}$ and $4 \mathrm{hr}$ incubation in medium containing $0.1 \mathrm{~mm}$ chloroquine. Cells were then kept in Dulbecco's modified Eagle medium (DMEM) $/ 0.5 \%$ serum for $42 \mathrm{hr}$; for serum stimulation, cells were refed with medium containing $15 \%$ FCS for $8 \mathrm{hr}$. Cell extracts were prepared by standard methods, and $40 \mu \mathrm{g}$ was analyzed for CAT and $\beta$-galactosidase activities (Sambrook et al. 1989); $\beta$-galactosidase activities varied $<1.5$-fold between individual transfections.

\section{Other procedures}

RNA preparation and analysis, DNA sequencing, and oligonucleotide labeling were performed by standard methods (Sambrook et al. 1989). In vitro translation of capped synthetic mRNAs, binding site selection, gel mobility-shift assays, and nuclear extract preparation were as described previously (Dignam et al. 1983; Norman et al. 1988; Pollock and Treisman 1.990); 
DNA binding reactions contained $0.2 \mu \mathrm{g}$ of poly [d(I-C)]. DEPC interference was performed as described (Sturm et al. 1987) by using probes made by PCR from plasmids containing the N1OWT and MCK oligonucleotides inserted into the $X b a I$ site of pBLCAT2.

\section{Acknowledgments}

We thank Susan John for assistance with tissue culture and transfections, Mike Sternberg for the data base search, Mike Owen for the gift of the Jurkat cell cDNA library, and Steve Goodbourn, Nic Jones, and members of the laboratory for helpful comments on the manuscript.

The publication costs of this article were defrayed in part by payment of page charges. This article must therefore be hereby marked "advertisement" in accordance with 18 USC section 1734 solely to indicate this fact.

\section{References}

Ammerer, G. 1990. Identification, purification, and cloning of a polypeptide (PRTF/GRM) that binds to mating-specific promoter elements in yeast. Genes \& Dev. 4: 299-312.

Angel, P., K. Hattori, T. Smeal, and M. Karin. 1988. The jun proto-oncogene is positively autoregulated by its product, Jun/AP-1. Cell 55: 875-885.

Bender, A. and G.J. Sprague. 1987. MAT alpha 1 protein, a yeast transcription activator, binds synergistically with a second protein to a set of cell-type-specific genes. Cell50: 681-691.

Boshart, M., F. Weber, G. Jahn, H.K. Dorsch, B. Fleckenstein, and W. Schaffner. 1985. A very strong enhancer is located upstream of an immediate early gene of human cytomegalovirus. Cell 41: 521-530.

Boxer, L.M., R. Prywes, R.G. Roeder, and L. Kedes. 1989. The sarcomeric actin CArG-binding factor is indistinguishable from the c-fos serum response factor. Mol. Cell. Biol. 9: 515522.

Braun, T., E. Tannich, D.G. Buschhausen, and H.H. Arnold. 1989. Promoter upstream elements of the chicken cardiac myosin light-chain 2-A gene interact with trans-acting regulatory factors for muscle-specific transcription. Mol. Cell. Biol. 9: 2513-2525.

Brun, G., V.N. La, J.P. Dangy, and M. Castellazzi. 1989. Nucleotide sequence of the quail c-jun protooncogene. Nucleic Acids Res. 17: 6393

Changelian, P.S., P. Feng, T.C. King, and J. Milbrandt. 1989. Structure of the NGFI-A gene and detection of upstream sequences responsible for its transcriptional induction by nerve growth factor. Proc. Natl. Acad. Sci. 86: 377-381.

Courey, A.J., D.A. Holtzman, S.P. Jackson, and R. Tjian. 1989. Synergistic activation by the glutamine-rich domains of human transcription factor Spl. Cell 59: 827-836.

Dignam, J.D., R.M. Lebovitz, and R.G. Roeder. 1983. Accurate transcription initiation by RNA polymerase II in a soluble extract from isolated mammalian nuclei. Nucleic Acids Res. 11: $1475-1489$.

Donoghue, M., H. Ernst, B. Wentworth, G.B. Nadal, and N. Rosenthal. 1988. A muscle-specific enhancer is located at the $3^{\prime}$ end of the myosin light-chain $1 / 3$ gene locus. Genes \& Dev. 2: 1779-1790.

Dubois, E., J. Bercy, and F. Messenguy. 1987a. Characterization of two genes, ARGRI and ARGRIII required for specific regulation of arginine metabolism in yeast. Mol. Gen. Genet. 207: 142-148.

Dubois, E., J. Bercy, F. Descamps, and F. Messenguy. 1987b. Characterization of two new genes essential for vegetative growth in Saccharomyces cerevisiae: Nucleotide sequence determination and chromosome mapping. Gene 55: 265-275.
Eliopoulos, E.E., A.J. Geddes, M. Brett, D.J.C. Pappin, and J.B.C. Findley. 1982. A structural model of the chromophore binding domain of ovine rhodopsin. Int. I. Biol. Macromol. 4: $263-268$.

Enoch, T., K. Zinn, and T. Maniatis. 1986. Activation of the human beta-interferon gene requires an interferon-inducible factor. Mol. Cell. Biol. 6: 801-810.

Errede, B. and G. Ammerer. 1989. STE12, a protein involved in cell-type-specific transcription and signal transduction in yeast, is part of protein-DNA complexes. Genes \& Dev. 3: 1349-1361.

Evan, G.I., G.K. Lewis, G. Ramsay, and J.M. Bishop. 1985. Isolation of monoclonal antibodies specific for human c-myc proto-oncogene product. Mol. Cell. Biol. 5: 3610-3616.

Flemington, E. and S.H. Speck. 1990. Identification of phorbol ester response elements in the promoter of Epstein-Barr virus putative lytic switch gene BZLF1. I. Virol. 64: 1217-1226.

Gossett, L.A., D.J. Kelvin, E.A. Sternberg, and E.N. Olson. 1989. A new myocyte-specific enhancer-binding factor that recognizes a conserved element associated with multiple musclespecific genes. Mol. Cell. Biol. 9: 5022-5033.

Graham, R. and M. Gilman. 1991. Distinct protein targets for signals acting at the c-fos serum response element. Science 251: 189-192.

Hattori, K., P. Angel, B.M. Le, and M. Karin. 1988. Structure and chromosomal localization of the functional intronless human JUN proto-oncogene. Proc. Natl. Acad. Sci. 85: 91489152.

Hayes, T.E., P. Sengupta, and B.H. Cochran. 1988. The human c-fos serum response factor and the yeast factors GRM/PRTF have related DNA binding specificities. Genes \& Dev. 2: 1713-1722.

Hazel, T.G., D. Nathans, and L.F. Lau. 1988. A gene inducible by serum growth factors encodes a member of the steroid and thyroid hormone receptor superfamily. Proc. Natl. Acad. Sci. 85: 8444-8448.

Herrera, R.E., P.E. Shaw, and A. Nordheim. 1989. Occupation of the $\mathrm{c}$-fos serum response element in vivo by a multi-protein complex is unaltered by growth factor induction. Nature 340: $68-70$.

Hobson, G.M., M.T. Mitchell, G.R. Molloy, M.L. Pearson, and P.A. Benfield. 1988. Identification of a novel TA-rich DNA binding protein that recognizes a TATA sequence within the brain creatine kinase promoter. Nucleic Acids Res. 16: $8925-8944$.

Hobson, G.M., G.R. Molloy, and P.A. Benfield. 1990. Identification of cis-acting regulatory elements in the promoter region of the rat brain creatine kinase gene. Mol. Cell. Biol. 10: $6533-6543$.

Horlick, R.A. and P.A. Benfield. 1989. The upstream musclespecific enhancer of the rat muscle creatine kinase gene is composed of multiple elements. Mol. Cell. Biol. 9: 2396-2413.

Horlick, R.A., G.M. Hobson, J.H. Patterson, M.T. Mitchell, and P.A. Benfield. 1990. Brain and muscle creatine kinase genes contain common TA-rich recognition protein-binding regulatory elements. Mol. Cell. Biol. 10: 4826-4836.

Jeang, K.T., D.R. Rawlins, P.J. Rosenfeld, J.H. Shero, T.J. Kelly, and G.S. Hayward. 1987. Multiple tandemly repeated binding sites for cellular nuclear factor 1 that surround the major immediate-early promoters of simian and human cytomegalovirus. J. Virol. 61: 1559-1570.

Keleher, C.A., C. Goutte, and A.D. Johnson. 1988. The yeast cell-type-specific repressor alpha 2 acts cooperatively with a non-cell-type-specific protein. Cell 53: 927-936.

Keleher, C.A., S. Passmóre, and A.D. Johnson. 1989. Yeast repressor alpha 2 binds to its operator cooperatively with yeast 
protein Mcml. Mol. Cell. Biol. 9: 5228-5230.

Krissansen, G.W., M.J. Owen, W. Verbi, and M.J. Crumpton. 1986. Primary structure of the T3 gamma subunit of the $\mathrm{T} 3 / \mathrm{T}$ cell antigen receptor complex deduced from cDNA sequences: Evolution of the T3 gamma and delta subunits. EMBO I. 5: 1799-1808.

Leung, S. and N.G. Miyamoto. 1989. Point mutational analysis of the human c-fos serum response factor binding site. $\mathrm{Nu}$ cleic Acids Res. 17: 1177-1195.

Luckow, B. and G. Schutz. 1987. CAT constructions with multiple unique restriction sites for the functional analysis of eukaryotic promoters and regulatory elements. Nucleic Acids Res. 15: 5490.

Ma, H., M.F. Yanofsky, and E.M. Meyerowitz. 1991. AGL1AGL6, an Arabidopsis gene family with similarity to floral homeotic and transcription factor genes. Genes \& Dev. 5: 484-495.

Manak, J.R. and R. Prywes. 1991. Mutation of serum response factor phosphorylation sites and the mechanism by which its DNA binding activity is increased by casein kinase II. Mol. Cell. Biol. 7: 3652-3659.

Manak, J.R., N. de Bisschop, R.M. Kris, and R. Prywes. 1990. Casein kinase II enhances the DNA binding activity of serum response factor. Genes \& Dev. 4: 955-967.

Marais, R., J. Wynne, C. McGuigan, and R. Treisman. 1991. Casein kinase II phosphorylation increases the rate of serum response factor-binding site exchange. $E M B O /$. (in press).

Mermod, N., E.A. O'Neill, T.J. Kelly, and R. Tjian. 1989. The proline-rich transcriptional activator of CTF/NF-I is distinct from the replication and DNA-binding domain. Cell 58: 741-753.

Milbrandt, J. 1988. Nerve growth factor induces a gene homologous to the glucocorticoid receptor gene. Neuron 1: 183188.

Minty, A. and L. Kedes. 1986. Upstream regions of the human cardiac actin gene that modulate its transcription in muscle cells: Presence of an evolutionarily conserved repeated motif. Mol. Cell. Biol. 6: 2125-2136.

Mueller, P.R. and B. Wold. 1989. In vivo footprinting of a muscle specific enhancer by ligation mediated PCR /published erratum in 248: 802, 1990) Science 246: 780-786.

Norman, C., M. Runswick, R. Pollock, and R. Treisman. 1988. Isolation and properties of cDNA clones encoding SRF, a transcription factor that binds to the $\mathrm{c}$-fos serum response element. 55: 989-1003.

Ohkuma, Y., M. Horikoshi, R.G. Roeder, and C. Desplan. 1990. Engrailed, a homeodomain protein, can repress in vitro transcription by competition with the TATA box-binding protein transcription factor IID. Proc. Natl. Acad. Sci. 87: 22892293.

Passmore, S., G.T. Maine, R. Elble, C. Christ, and B.K. Tye. 1988. Saccharomyces cerevisiae protein involved in plasmid maintenance is necessary for mating of MAT alpha cells. J. Mol. Biol. 204: 593-606.

Passmore, S., R. Elble, and B.K. Tye. 1989. A protein involved in minichromosome maintenance in yeast binds a transcriptional enhancer conserved in eukaryotes. Genes \& Dev. 3: 921-935.

Pollock, R. and R. Treisman. 1990. A sensitive method for the determination of protein-DNA-binding specificities. $\mathrm{Nu}$ cleic Acids Res. 18: 6197-6204.

Ryseck, R.P., B.H. Macdonald, M.G. Mattei, S. Ruppert, and R. Bravo. 1989. Structure, mapping and expression of a growth factor inducible gene encoding a putative nuclear hormonal binding receptor. EMBO $J .8:$ 3327-3335.

Sambrook, J., E. Fritsch, and T.Maniatis. 1989. Molecular clon- ing: A laboratory manual, 2nd ed. Cold Spring Harbor Laboratory Press, Cold Spring Harbor, New York.

Sartorelli, V., K.A. Webster, and L. Kedes. 1990. Muscle-specific expression of the cardiac alpha-actin gene requires MyoD1, CArG-box binding factor, and Spl. Genes \& Dev. 4: 18111822.

Schroter, H., C.G. Mueller, K. Meese, and A. Nordheim. 1990. Synergism in ternary complex formation between the dimeric glycoprotein p67SRF, polypeptide p62TCF and the c-fos serum response element. EMBO J. 9: 1123-1130.

Schwarz-Sommer, Z., P. Huijser, W. Nacken, H. Saedler, and H. Sommer. 1990. Genetic control of flower development by homeotic genes in Antirrhinum majus. Science 250: 931936.

Shaw, P.E., H. Schroter, and A. Nordheim. 1989. The ability of a ternary complex to form over the serum response element correlates with serum inducibility of the human c-fos promoter. Cell 56: 563-572.

Smith, D.B. and K.S. Johnson. 1988. Single-step purification of polypeptides expressed in Escherichia coli as fusions with glutathione $S$-transferase. Gene 67: 31-40.

Sommer, H., J.P. Beltran, P. Huijser, H. Pape, W.E. Lonnig, H. Saedler, and S.Z. Schwarz. 1990. Deficiens, a homeotic gene involved in the control of flower morphogenesis in Antirrhinum majus: The protein shows homology to transcription factors. EMBO I. 9: 605-613.

Sompayrac, L.M. and K.J. Danna. 1981. Efficient infection of monkey cells with DNA of simian virus 40. Proc. Natl. Acad. Sci. 78: 7575-7578.

Sturm, R., T. Baumruker, B.J. Franza, and W. Herr. 1987. A $100-\mathrm{kD} H e L a$ cell octamer binding protein (OBP100) interacts differently with two separate octamer-related sequences within the SV40 enhancer. Genes \& Dev. 1: 1147-1160.

Tan, S., G. Ammerer, and T.J. Richmond. 1988. Interactions of purified transcription factors: Binding of yeast MAT alpha 1 and PRTF to cell type-specific, upstream activating sequences. EMBO I. 7: 4255-4264.

Taylor, M., R. Treisman, N. Garrett, and T. Mohun. 1989. Muscle-specific (CArG) and serum-responsive (SRE) promoter elements are functionally interchangeable in Xenopus embryos and mouse fibroblasts. Development 106: 67-78.

Treisman, R. 1990. The SRE: A growth factor responsive transcriptional regulator. Sem. Cancer Biol. 1 47-58.

Tuil, D., N. Clergue, D. Montarras, C. Pinset, A. Kahn, and F. Phan-Dinh-Tuy. 1990. CC Ar GG boxes, cis-acting elements with a dual specificity. Muscle-specific transcriptional activation and serum responsiveness. J. Mol. Biol. 213: 677-686.

Walsh, K. 1989. Cross-binding of factors to functionally different promoter elements in c-fos and skeletal actin genes. Mol. Cell. Biol. 9: 2191-2201.

Walsh, K. and P. Schimmel. 1988. DNA-binding site for two skeletal actin promoter factors is important for expression in muscle cells. Mol. Cell. Biol. 8: 1800-1802.

Wentworth, B.M., M. Donoghue, J.C. Engert, E.B. Berglund, and N. Rosenthal. 1991. Paired MyoD binding sites regulate myosin light chain gene expression. Proc. Nat. Acad. Sci. 88: 1242-1246.

Yanofsky, M.F., H. Ma, J.L. Bowman, G.N. Drews, K.A. Feldmann, and E.M. Meyerowitz. 1990. The protein encoded by the Arabidopsis homeotic gene agamous resembles transcription factors. Nature 346: 35-39.

Zhu, H., A. Garcia, R. Ross, S. Evans, and K. Chien. 1991. A conserved 28-base pair element (HF-1) in the rat cardiac myosin light-chain-2 gene confers cardiac-specific and a adrenergic-inducible expression in cultured neonatal rat myocardial cells. 11: 2273-2281. 


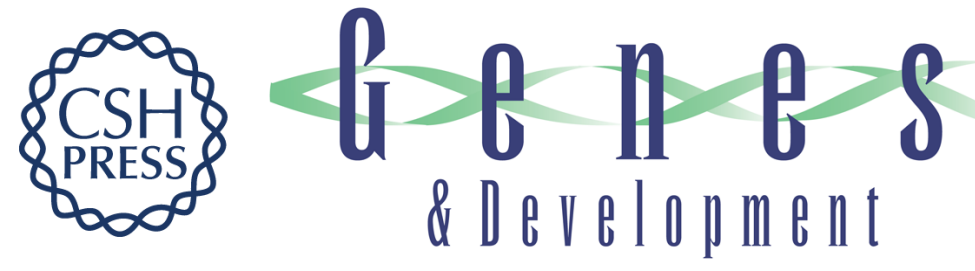

\section{Human SRF-related proteins: DNA-binding properties and potential regulatory targets.}

$\mathrm{R}$ Pollock and $\mathrm{R}$ Treisman

Genes Dev. 1991, 5:

Access the most recent version at doi:10.1101/gad.5.12a.2327

References This article cites 62 articles, 33 of which can be accessed free at:

http://genesdev.cshlp.org/content/5/12a/2327.full.html\#ref-list-1

License

Email Alerting

Service

Receive free email alerts when new articles cite this article - sign up in the box at the top right corner of the article or click here.

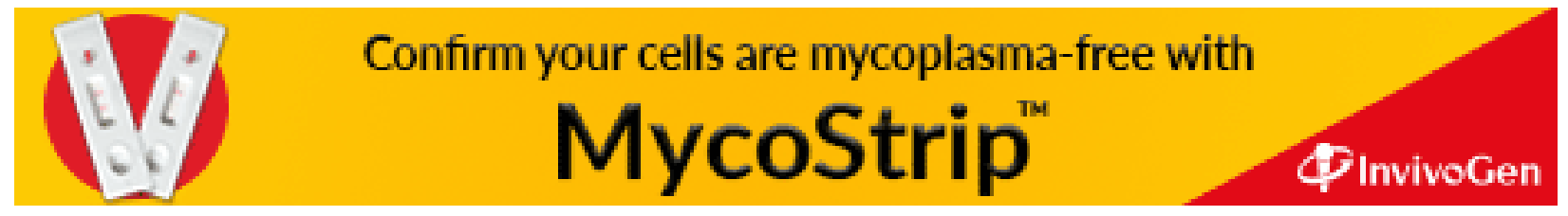

